\title{
Costs of breeding are rapidly buffered and do not affect migratory behavior in a long-lived bird species
}

\author{
Raül Ramos iD,${ }^{1,3}$ Victoria Llabrés, ${ }^{1}$ Laura Monclús, ${ }^{2}$ Manel LóPez-BÉJar, ${ }^{2}$ and Jacob GonZÁlez-Solís ${ }^{1}$ \\ ${ }^{1}$ Department of Evolutionary Biology, Ecology and Environmental Sciences (BEECA), Faculty of Biology, Biodiversity Research Institute \\ (IRBio), Universitat de Barcelona, Av Diagonal 643, 08028 Barcelona, Spain \\ ${ }^{2}$ Department of Animal Health and Anatomy, Veterinary Faculty, Universitat Autònoma de Barcelona, 08193 Bellaterra, Spain
}

\begin{abstract}
Life history theory states that individual fitness in one stage of life is conditioned by what occurred in previous stages. In migratory species, reproductive effort during breeding has often been found to influence body condition, molt schedule, self-provisioning and migration of individuals in subsequent seasons (i.e., carryover effects of breeding). However, there is a current uncertainty in understanding how long-distance migrants trade off among such energy-demanding activities (i.e., breeding, molting and migrating). To provide evidence to the field, we experimentally reduced the parental effort of a long-lived Procellariform, the Cory's shearwater (Calonectris borealis), by inducing failure at the incubation stage. Treatment and control birds were tracked during their subsequent migration by means of light-level and immersion loggers and sampled for six specific feathers (molted at different periods along the migratory cycle) upon the recovery of the loggers $1 \mathrm{yr}$ later. Feathers were used to perform stable isotope analysis (SIA) and determine corticosterone levels (CORT). By these means, we evaluated the effect of breeding effort on migratory strategy, at-sea activity patterns, molt patterns, and levels of stress experienced by birds along the non-breeding period. We did not detect any difference between birds in the induced failure group and successful breeders in terms of spatio-temporal distribution: all birds shared common foraging areas throughout the study period and the timing of major phenological events did not differ. Failed birds significantly advanced their molt, as revealed by SIA and flying activity patterns. The stress levels of failed birds, inferred through CORT concentrations in feathers, were found to be consistently lower than in successful breeders, through the end of the breeding to the non-breeding period. Thus, we provide robust evidence that the costs of reproduction can be physiologically mediated from the breeding to the non-breeding period through molting schedules and CORT levels. However, we failed to detect clear effects on migratory behavior or subsequent breeding success, suggesting that costs of breeding in long-lived species may be rapidly buffered during the post-breeding period, as would be expected from life history theory.
\end{abstract}

Key words: breeding failure; carryover effects; Cory's shearwater; feather corticosterone; long-distance migrants; molting strategy; oceanic migrations; seasonal interactions; stable isotope analysis.

\section{INTRODUCTION}

Life history theory predicts that individual fitness in one stage of life depends on access to resources, or the manner in which they are allocated, in previous stages (Stearns 1992, Lindström 1999, Metcalfe and Monaghan 2001). In longdistance migratory species, individual life histories are shaped by events and selective pressures acting in geographically disparate places during the breeding, migration and wintering periods (Runge and Marra 2005, Norris and Marra 2007). Thus, considering only within-season constraints of migratory species may be over-simplistic, as events occurring in a given period of the annual cycle carry over to influence other events in subsequent seasons (Rushing et al. 2017).

There is mounting evidence of carryover effects from the breeding to the non-breeding period, suggesting that molting and migratory behavior are influenced by the previous breeding effort (Table 1). Studies on small and short-lived songbirds have suggested carryover effects of breeding on

Manuscript received 9 February 2018; revised 23 May 2018; accepted 11 June 2018. Corresponding Editor: Emily DuVal.

${ }^{3}$ E-mail: ramos@ub.edu molting schedules, migration departure dates, or even on the non-breeding destinations of migratory species (Nilsson and Svensson 1996, Dawson et al. 2000, Mitchell et al. 2012). More recently, some experimental and observational studies on larger long-lived migrants, such as seabirds, have also demonstrated the existence of carryover in such large species (Garthe et al. 2012, Catry et al. 2013a, Fayet et al. 2016). Theoretically, life history theory predicts that short-lived species, with lower chances to survive until the next breeding attempt than long-lived species, should invest as much as possible in current reproductive events, even when this effort may compromise their survival for future breeding attempts (Lindén and Moller 1989, Stearns 1992). Therefore, we would expect carryover effects from the breeding to the nonbreeding period and to the subsequent breeding attempts to be more persistent and stronger in short-lived species. Empirically, however, evidence suggests that both short- and long-lived species experience carryover effects, in similar proportions (Table 1).

Typically, successful breeders are considered to have invested greater effort than failed or sabbatical breeders, delaying their departure from breeding grounds, their arrival to the wintering grounds and their departure from the wintering grounds (Phillips et al. 2005, Bogdanova et al. 2011, 
TABLE 1. A selection of studies from migratory birds describing carryover effects of breeding effort on several aspects in subsequent seasons: molt schedule, migration schedule, non-breeding grounds, and subsequent breeding attempt.

\begin{tabular}{|c|c|c|c|c|c|c|}
\hline & \multicolumn{4}{|c|}{ Breeding effort impact on } & \multirow[b]{2}{*}{ Study } & \multirow[b]{2}{*}{ Reference } \\
\hline & $\begin{array}{c}\text { Molt } \\
\text { schedule }\end{array}$ & $\begin{array}{l}\text { Migration } \\
\text { schedule }\end{array}$ & $\begin{array}{l}\text { Non-breeding } \\
\text { grounds }\end{array}$ & $\begin{array}{c}\text { Subsequent } \\
\text { breeding effort }\end{array}$ & & \\
\hline \multicolumn{7}{|l|}{ Short-lived species } \\
\hline Wood thrush, Hylocichla mustelina & Yes & No & - & - & Observ. & Stutchbury et al. (2011) \\
\hline Wood thrush, Hylocichla mustelina & - & - & Yes & Yes & Observ. & Rushing et al. (2017) \\
\hline $\begin{array}{l}\text { Savannah sparrow, } \\
\text { Passerculus sandwichensis }\end{array}$ & - & Yes & - & - & Observ. & Mitchell et al. (2012) \\
\hline American redstart, Setophaga ruticilla & Yes & - & - & - & Observ. & Norris et al. (2004) \\
\hline European starling, Sturnus vulgaris & Yes & - & - & - & Experim. & Dawson et al. (2000) \\
\hline \multicolumn{7}{|l|}{ Long-lived species } \\
\hline $\begin{array}{l}\text { Light-bellied Brent goose, } \\
\text { Branta bernicla }\end{array}$ & - & - & Yes & Yes & Observ. & Inger et al. (2010) \\
\hline Cory's shearwater, Calonectris borealis & - & Yes & Yes & - & Experim. & Catry et al. (2013a) \\
\hline Cory's shearwater, Calonectris borealis & Yes & No & No & No & Experim. & This study \\
\hline Northern gannets Morus bassanus & - & - & - & Yes & Observ. & Fairhurst et al. (2017) \\
\hline Sooty shearwater, Puffinus griseus & - & Yes & - & - & Observ. & Hedd et al. (2012) \\
\hline Manx shearwater, Puffinus puffinus & - & Yes & - & Yes & Experim. & Fayet et al. (2016) \\
\hline Black-legged kittiwake, Rissa tridactyla & - & Yes & - & - & Experim. & Schultner et al. (2014) \\
\hline Black-legged kittiwake, Rissa tridactyla & - & Sometimes & Yes & No & Observ. & $\begin{array}{l}\text { Bogdanova et al. (2011, } \\
\text { 2017) }\end{array}$ \\
\hline $\begin{array}{l}\text { Grey-headed albatrosses } \\
\text { Thalassarche chrysostoma }\end{array}$ & - & Yes & Yes & - & Observ. & Clay et al. (2016) \\
\hline $\begin{array}{l}\text { Grey-headed albatrosses } \\
\text { Thalassarche chrysostoma }\end{array}$ & - & - & - & No & Observ. & Crossin et al. (2017) \\
\hline $\begin{array}{l}\text { Black-browed albatross, } \\
\text { Thalassarche melanophrys }\end{array}$ & - & Yes & - & - & Observ. & Phillips et al. (2005) \\
\hline $\begin{array}{l}\text { Black-browed albatross, } \\
\text { Thalassarche melanophrys }\end{array}$ & - & - & - & Yes & Observ. & Crossin et al. (2017) \\
\hline
\end{tabular}

Notes: Species are split according to their life span, i.e. short- or long-lived species. Observ., observational studies; Experim., experimental studies.

Catry et al. 2013a). In addition, non-breeding destinations and feeding behavior during the non-breeding period may also differ (Bogdanova et al. 2011, Catry et al. 2013a). Individuals in better body condition at the end of the breeding period (e.g., early failed or sabbatical breeders) may have more energy (and time) at their disposal to seek better wintering grounds, and may be more prone to engage in longer migrations far from breeding grounds (Bogdanova et al. 2011). Flying activity during part of or the entire non-breeding period may also differ in birds that are free of parental duties early in the breeding season (Daunt et al. 2006, Fayet et al. 2016). Such failed breeder birds may simply fly less because of their better body condition and because their energetic demands are lower throughout the non-breeding period (Daunt et al. 2014). Alternatively, this may be the result of flight impairment due to an advanced/earlier molt (Cherel et al. 2016). It is well known that most birds molt during the non-breeding period to avoid overlap of molting with other energetically demanding processes, such as reproduction or migration (Barta et al. 2008). In this regard, many large seabirds delay the onset of molt of their flight feathers as much as possible, but their long wings force them to start molting the first primaries at the end of reproduction in order to complete molting during the non-breeding period and before departing to the breeding grounds (Bridge 2006, Edwards 2008). Failed or sabbatical breeders, however, free from their breeding duties, often start molting earlier
(Alonso et al. 2009, Catry et al. 2013b), thus reaching their wintering destinations with less pressure on molting schedules, allowing them to conserve more energy for the next breeding attempt. However, experimental evidence linking breeding effort to molting schedules is lacking, possibly due to the challenges of recording the molting stage of birds in the open sea.

Finally, the mechanisms mediating such carryover effects are not yet clear. It is suggested that, in vertebrates, a complex of three endocrine glands (i.e., the hypothalamic-pituitary-adrenal axis) reacts against diverse, external stressors. It is thought to be responsible for the regulation of energy levels (and nutrient acquisition) through secretion of glucocorticoid hormones, such as corticosterone (CORT) in birds (Romero 2004). Several examples suggest that CORT levels measured in animal tissues are useful indicators of diverse stressful responses, such as unfavorable environmental conditions (Romero 2004), low food availability (Kitaysky et al. 2010), poor diet quality (Kitaysky et al. 2001), intense foraging effort (Crossin et al. 2014), as well as increased activity budgets (Angelier et al. 2007). It is also known that such stress markers are deposited and measurable in keratinized tissues, such as feathers, and that the amount of CORT deposited in these tissues is correlated with stress levels experienced by individuals during tissue growth (Bortolotti et al. 2008, Jenni-eiermann et al. 2015, Aharon-Rotman et al. 2017). Thus, stressful events that occurred during molting 
(and retained in bird feathers) could act as mediators of behavior and performance in the subsequent season (Bourgeon et al. 2014, Harms et al. 2015, Pérez et al. 2016, Crossin et al. 2017, Young et al. 2017).

With all of these ideas in mind, we designed a field experiment in a long-lived Procellariiform seabird, Cory's shearwater Calonectris borealis, to understand how animals trade off breeding, molting and migrating activities and how these trade-offs are mediated. Specifically, we evaluated the effect of breeding effort on: (1) individual migratory strategy, (2) wintering ground each bird selected, (3) timing of subsequent key phenological events (all inferred through geolocation light data), (4) at-sea activity patterns during the non-breeding period (inferred through immersion data), (5) spatio-temporal patterns of molt (inferred through three isotopic signatures), and (6) levels of stress, as indicated by the CORT measurements on several feathers. According to the carryover hypothesis based on individual-level seasonal interactions, we expected that breeding effort would carry over to influence individual performance and success in the next season (Harrison et al. 2011). We therefore predicted that failed birds would start their molt soon after the breeding failure, which would allow birds to complete (or at least advance) their molt before departing on their migration compared to a more delayed molt of successful breeders. This would allow failed breeders to avoid overlapping this demanding activity as much as possible with their migration journey, as molting can also impair flight to some extent. In addition, we also expected failed birds to migrate to the wintering destinations earlier and to recover earlier from their lower breeding effort compared to successful breeders, allowing failed breeders to return earlier to the breeding grounds after the wintering period. This would, in turn, increase the probability of a subsequent successful reproduction. Finally, we expected failed breeders to experience lower stress levels than successful breeders due to their lower breeding effort, and therefore to show lower CORT concentrations in their feathers than successful breeders.

\section{Methods}

\section{Model species}

The Cory's shearwater is a medium-sized Procellariiform species that has a long lifespan of over $30 \mathrm{yr}$ (Ramos et al. 2012). The species is a colonial pelagic petrel, highly monogamous, with strong phylopatry and interannual breeding burrow fidelity. It breeds annually in remote islets and islands across Macaronesia (Thibault et al. 1997). Adults arrive at the colony in late February or early March, females lay a single egg in early June, both mates share incubation duties, and chicks hatch in mid-late July and fledge in late October (Thibault et al. 1997). In general, this shearwater undertakes long and rapid transoceanic migrations from its Macaronesian breeding grounds to its wintering areas in the North, Central and South Atlantic Ocean, even reaching the Indian Ocean (González-Solís et al. 2007, Dias et al. 2011). The species has been defined as a partial migrant given that a relevant proportion of individuals remain at the breeding ground for wintering. The migratory plasticity of the species has been linked to individual breeding performance, with successful breeders being more prone to undertake long-distance migrations than failed breeders (Catry et al. 2013a). Additionally, it is also suggested that breeding performance of the species is likely to influence the molting strategy of individuals (Alonso et al. 2009), although this has not been tested experimentally. Such characteristics make Cory's shearwater an ideal model species to investigate seasonal interactions and carryover effects.

\section{Experimental protocol and sampling design}

The present study and fieldwork experiments were conducted in a Cory's shearwater colony in Gran Canaria, Canary Archipelago, Spain (154 $47^{\prime} 18^{\prime \prime} \mathrm{N} ; 27^{\circ} 50^{\prime} 41^{\prime \prime} \mathrm{E}$, permit issue: 1151/25775, Cabildo de Gran Canaria). During the incubation period of 2014, we artificially modified the breeding performance of adult breeders by inducing breeding failure (Golet et al. 2004, Boulinier et al. 2008). First, we randomly selected 15 burrows (among 220), and during daylight in the early incubation phase (in mid-late June), we removed the egg that one adult was incubating. These eggs were fostered to non-study pairs whose eggs had been predated by rats or who were incubating a broken or unhatched egg (assumed to be infertile or with a dead embryo). Experimental birds that were incubating left the burrow the night following egg removal, and their partners only visited the burrow one or two nights subsequently, after which point the burrow was completely abandoned. Regarding the pairs that received an experimental egg, twelve of them rapidly accepted the new egg, and resumed incubation immediately. In only three cases, adults left the new egg unattended for more than 20 consecutive days. Hatching rate for such receptor pairs was $60 \%$, similar to that recorded for control burrows in the same year (52\%). Simultaneously, 14 untreated burrows that successfully fledged a chick were included in the study as control pairs to compare and evaluate the cost of breeding and its derivable consequences for migration.

In 2014, every adult shearwater included in the study (i.e., from both treatments, failed and successful breeders) was fitted with a small, leg-mounted, combined geolocatorimmersion logger (Intigeo-C250 from Migrate Technology Ltd, Cambridge, UK). The weight of these geolocators ( $2.6 \mathrm{~g}$ ) corresponded to $0.3-0.4 \%$ of bird body mass, thus well below the threshold of $3 \%$ above which deleterious effects are more likely to occur (Phillips et al. 2003). These loggers recorded elapsed time, light intensity and saltwater immersion.

In 2015, we recovered 30 and 26 geolocators from experimental/failed breeders and control/successful breeders, respectively, and downloaded useful (light and immersion) data from 30 and 24 individuals, respectively (Appendix S1: Table S1). Additionally, at the time of geolocator recovery, we sampled two entire feathers from every bird (the first primary feather, P1, and the thirteenth secondary feather, S13) for CORT determinations, and small basal portions $(\sim 10 \mathrm{~mm})$ of the following primaries: P1, P5, P9 from the right wing, and P3, P7 from the left one for stable isotope analysis (SIA). The purpose of the sampling of five primaries along the wing sequence was to assess individual molting patterns in relation to migratory movements, based 
on the differences in the isotopic ratios of the prey across water masses (Meier et al. 2017). We sampled on the right and left wings and removed only a small portion of each remige to minimize potential detrimental effects of the sampling on wing load. Primary feather renewal in the species occurs at the end of the breeding period simply and descending from the most proximal (P1) towards the most distal (P10) feather molted at the end of the non-breeding period, and in a fairly synchronous way between wings (Ramos et al. 2009b). Thus, we assumed that all P1s were molted at the breeding grounds, whereas all $\mathrm{P} 9 \mathrm{~s}$ were molted at the non-breeding grounds. Since isotopic signatures of feathers molted at the breeding and non-breeding grounds differ (Ramos et al. 2009b), we sampled primaries sequentially to assess the grounds where each feather was grown in relation to the individual migratory movements tracked by the geolocators. Secondary feathers in Cory's shearwater show a more complex molting pattern with at least three molting foci, but the most internal secondaries (e.g., S13) are known to be molted during the non-breeding season (Ramos et al. $2009 b$ ). Breeding success of every nest was also recorded in 2015, at the very end of the breeding season. All birds were sexed molecularly from blood samples (diagnostic kit from Durviz, Valencia, Spain).

\section{Geolocation data and location of non-breeding areas}

Intigeo-C250 geolocators measured light intensity every minute recording the maximum at $5 \mathrm{~min}$ intervals. Twilight events from raw light intensities were visually supervised and computed with Intiproc software from Migrate Technology Ltd (Coton, Cambridge, UK; Fox 2015). The sunrise and sunset times were estimated applying the light threshold value of 2. To estimate the sun elevation angle, we calibrated the loggers before deployment and after recovery on an open site without shade. The value of the sun elevation angle was determined individually for every geolocator with at-colony calibration data, ranging from -2.1 to -4 .4. Light level data were converted into latitude derived from day length and longitude derived from the time of local midday with respect to Greenwich Mean Time, using Intiproc software (Fox 2015). This process results in the estimation of two locations every day with a relatively low spatial accuracy $\left(\sim 2^{\circ}\right.$; Phillips et al. 2004). To filter unrealistic positions, we removed those that (1) resulted from long periods spent in burrows during incubation, (2) were obtained from light curves showing interference at dawn or dusk (visual inspection); (3) were within the $20 \mathrm{~d}$ closest to the equinoxes; or (4) resulted in unrealistic flight speeds ( $>40 \mathrm{~km} / \mathrm{h}$ sustained over $48 \mathrm{~h}$ ), using iterative backward/forward speed filtering routines (McConnell et al. 1992) written in R (R Development Core Team 2017).

The migration strategy followed by every bird was determined visually as: (1) resident, when the bird remained along the Canary Current throughout most of the non-breeding period; or (2) migratory, when the bird undertook a typical long-distance trip that lasted more than $60 \mathrm{~d}$ (including outward and return migrations; Table 2).

Non-breeding distributions were assessed through Kernel Density Estimations (KDEs; "kernelUD" function in the adehabitat v.1.8.7 package in R; Calenge 2006). They were
TABLE 2. Number of Cory's shearwaters (Calonectris borealis) included in the study. Birds are classified according to their migration strategy (resident or migratory), breeding success (induced failure or successful), and sex.

\begin{tabular}{lccccccr}
\hline \hline \multirow{2}{*}{$\begin{array}{l}\text { Migration } \\
\text { strategy }\end{array}$} & \multicolumn{3}{c}{ Induced failure } & & & \multicolumn{3}{c}{ Successful breeders } \\
\cline { 2 - 4 } \cline { 6 - 8 } & Females & Males & All & & Females & Males & All \\
\hline Resident & 4 & 2 & 6 & & 1 & 3 & 4 \\
Migratory & 11 & 13 & 24 & & 10 & 10 & 20 \\
\hline
\end{tabular}

calculated with data from 01 December to 31 January with a smoothing factor of $h=200$, which corresponds to the average accuracy of geolocation in km (Phillips et al. 2004). We used two Utilization Distributions (UDs) from kernel analysis: $50 \%$ UDs as proxies of core areas of the non-breeding habitat used by every bird (Fig. 1; Lascelles et al. 2016), and $5 \%$ UDs to estimate the centroids of the non-breeding range of every individual.

Most phenological events, such as timing of departure and arrival of individual birds at breeding and non-breeding grounds, as well as timing of crossing the parallel at $10^{\circ} \mathrm{N}$ in both outward and return migrations, were determined visually from spatial data of those migratory birds with complete tracks $(n=28$; Table 3 and Fig. 2). Departure dates were assessed as the first day when the bird's location was outside the cluster of positions of the previous days that corresponded to the staging area (either breeding or non-breeding), followed by directional movement away from this area. Similarly, arrival dates were considered to be the first day of return to the staging region after a directed movement towards that area. Last night in the burrow and first night in the colony were assessed for all birds using activity data (see below for specifications). We quantified these two variables for every bird as the last night between July and October that accounted for at least three consecutive hours of darkness in dry mode, and the first night between February and June that accounted for at least four consecutive hours of darkness in dry mode, respectively. Additionally, non-breeding ranges were estimated individually as orthometric distance between the breeding colony and the average of all non-breeding positions within the $5 \% \mathrm{UD}$ (in $\mathrm{km}$ ). Thus, we estimated up to 10 phenological and spatial parameters for every complete migration cycle (Table 3 ). We used $Q-Q$ plots to check for normality of the distributions of these variables (by treatment and sex). We evaluated the effect of treatment and sex on values of these phenological parameters by fitting a set of two-way analyses of variance (ANOVA) tests, where each of the ten parameters described above was the response variable, and treatment and sex (including their interaction) were the main explanatory variables (Table 3). ANOVAs were conducted in $\mathrm{R}$ version 2.8.1 ( $\mathrm{R}$ Development Core Team 2017).

\section{At-sea activity data}

The geolocation loggers also tested for immersion in sea water every $6 \mathrm{~s}$ using 2 electrodes, and recorded any change of state from wet to dry or dry to wet. From this data, we assessed the daily time spent on water (wet) for every bird year-round. First, light and immersion data were used 

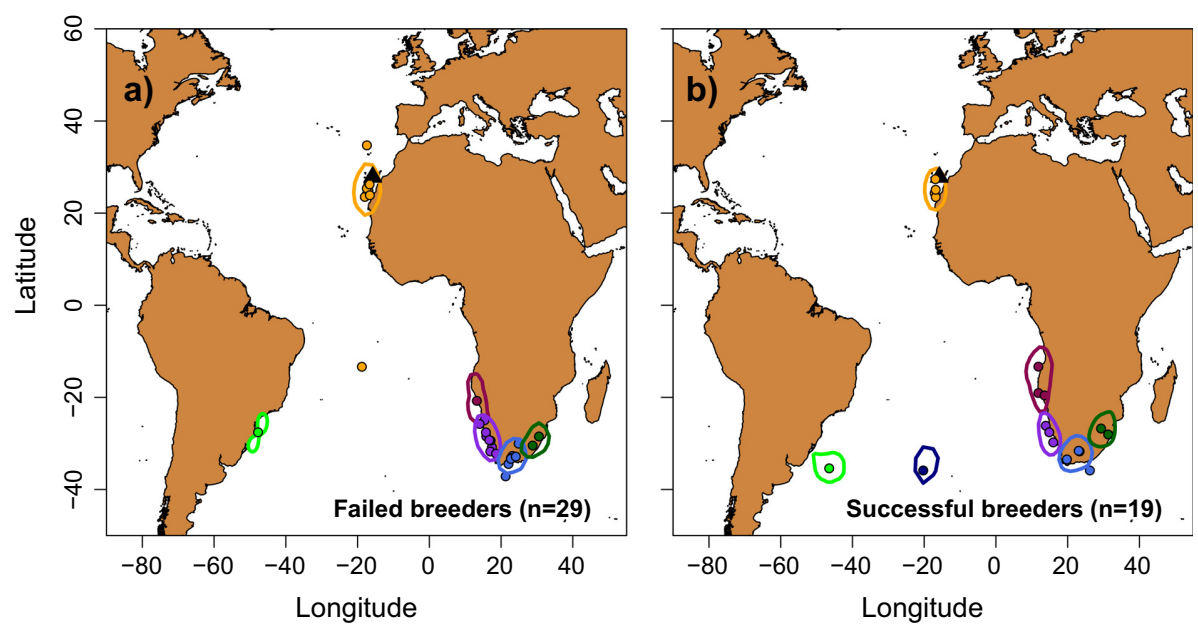

FIG. 1. Mean non-breeding positions (from 01 December to 31 January) of every (a) failed breeder (29 individuals) and (b) successful breeder (19 individuals) of Cory's shearwater (Calonectris borealis) with a complete track. Additionally, common wintering areas are depicted separately as kernel density distributions (50\% UDs) in different colors: the Canary Current in yellow, the Angola Current in magenta, the Benguela Current in purple, the Benguela-Agulhas confluence in light blue, the Agulhas Current in dark green, the South Central Atlantic in dark blue, and the Brazil Current in light green. Colony location (Gran Canaria) is shown with a black triangle. The migratory strategy of individuals, i.e., staying in the Canary Current (resident) or migrating to distant non-breeding grounds for wintering, did not differ significantly between the treatment groups.

TABLE 3. Main phenological and nest attendance variables of birds included in the experiment.

\begin{tabular}{|c|c|c|c|c|c|}
\hline \multirow[b]{2}{*}{ Variable } & \multicolumn{2}{|c|}{ Treatment group } & \multicolumn{3}{|c|}{ Statistics } \\
\hline & Failed breeders & Successful breeders & $F$ value & df & $P$-value \\
\hline Last night in the colony & $23 \mathrm{Sep} \pm 22.0(29)(02 \mathrm{Sep} \mid 30 \mathrm{Oct})$ & 02 Oct $\pm 14.5(23)(06 \mathrm{Sep} \mid 29$ Oct $)$ & 3.0 & 1,50 & 0.088 \\
\hline Departure long-distance migration & 14 Nov $\pm 9.1(18)(03 \mathrm{Nov} \mid 07 \mathrm{Dec})$ & $14 \mathrm{Nov} \pm 11.8(10)(26 \mathrm{Oct} \mid 05 \mathrm{Dec})$ & 0.0 & 1,26 & 0.958 \\
\hline Crossing of $10 \mathrm{~N}$ parallel (Outward) & $17 \mathrm{Nov} \pm 6.9(18)(06 \mathrm{Nov} \mid 28 \mathrm{Nov})$ & $20 \mathrm{Nov} \pm 8.2(10)(10 \mathrm{Nov} \mid 06 \mathrm{Dec})$ & 0.8 & 1,26 & 0.386 \\
\hline Arrival at wintering area & $04 \mathrm{Dec} \pm 9.5(18)(21 \mathrm{Nov} \mid 01 \mathrm{Jan})$ & $07 \mathrm{Dec} \pm 9.1(10)(24 \mathrm{Nov} \mid 26 \mathrm{Dec})$ & 1.0 & 1,26 & 0.338 \\
\hline Days in the wintering area & $65.9 \pm 9.2(18)(40 \mid 77)$ & $62.6 \pm 9.9(10)(51 \mid 80)$ & 0.8 & 1,26 & 0.386 \\
\hline Non-breeding range (in km) & $5711.5 \pm 3120.1(28)(271.7 \mid 8193.3)$ & $5333.2 \pm 3063.1(20)(154.5 \mid 7990.6)$ & 0.2 & 1,46 & 0.678 \\
\hline Departure from the wintering area & $09 \mathrm{Feb} \pm 7.6(18)(31 \mathrm{Jan} \mid 24 \mathrm{Feb})$ & $09 \mathrm{Feb} \pm 8.5(10)(01 \mathrm{Feb} \mid 25 \mathrm{Feb})$ & 0.0 & 1,26 & 0.924 \\
\hline Crossing of 10N parallel (Return) & $14 \mathrm{Feb} \pm 7.8(18)(05 \mathrm{Feb} \mid 29 \mathrm{Feb})$ & $14 \mathrm{Feb} \pm 8.0(10)(06 \mathrm{Feb} \mid 29 \mathrm{Feb})$ & 0.0 & 1,26 & 0.955 \\
\hline Arrival to breeding area & $01 \mathrm{Mar} \pm 9.3(18)(15 \mathrm{Feb} \mid 17 \mathrm{Mar})$ & $02 \mathrm{Mar} \pm 7.7$ (10) (22 Feb|16 Mar) & 0.1 & 1,26 & 0.788 \\
\hline First night in the colony & $09 \mathrm{Feb} \pm 8.8(25)(02 \mathrm{Feb} \mid 28 \mathrm{Feb})$ & $15 \mathrm{Feb} \pm 15.0(17)(02 \mathrm{Feb} \mid 16 \mathrm{Mar})$ & 2.2 & 1,40 & 0.146 \\
\hline
\end{tabular}

Notes: Migratory variables only included migratory individuals, except "Last night in the colony" and "First night in the colony", which also included resident ones. Treatment group and sex effects, as well as their interaction were non-significant in the generalized linear models (GLM) for all of the variables we considered. For comparison purposes, we show results on treatment groups. Values are means \pm standard deviation, $\mathrm{SD}$ (in days), with sample sizes and ranges in parentheses.

simultaneously to (1) distinguish time spent at sea from time at the colony (darkness during daylight indicates the bird is in the burrow), and (2) estimate the percentage of time spent on the water as a proxy of resting time (Shaffer et al. 2001), separately for daylight and darkness periods. Secondly, and for plotting purposes, activity budgets were modeled using Generalized Additive Mixed Models (GAMMs; Fig. 3). We used the library mgev in $\mathrm{R}$, based on penalized regression splines and generalized cross-validation, to select the appropriate smoothing parameters (Wood and Augustin 2002). GAMMs combine the utilities of linear mixed models (Pinheiro and Bates 2000) and generalized additive models (Hastie and Tibshirani 1990) so that random factors, fixed factors and nonlinear predictor variables can all be estimated in the same statistical model. We included treatment and migratory strategy as fixed factors, date as a smooth term, and bird identity as a random term. This allowed us to determine cyclicity in the time spent on the water over the annual cycle (i.e., breeding, migrating, wintering, migrating, and breeding again). Third, as activity budgets varied seasonally (Fig. 3), we modeled the dynamics of time spent on the water for specific key periods throughout the annual cycle, such as September and February, using Generalized Linear Mixed Models (GLMMs; Table 5; Appendix S1: Fig. S1). September is a late breeding period with intense rearing duties for breeding birds, while in February the return migration of the species occurs (Thibault et al. 1997). For these periods, we evaluated the effect of treatment and migratory strategy (as fixed explanatory variables) on activity values (the response variable) by fitting a set of candidate GLMMs (Table 5). We excluded sex from the modeling as it has shown no effect on phenology or spatial distribution. To account for individual heterogeneity in activity budgets, bird identity was included as a random term. Gaussian 


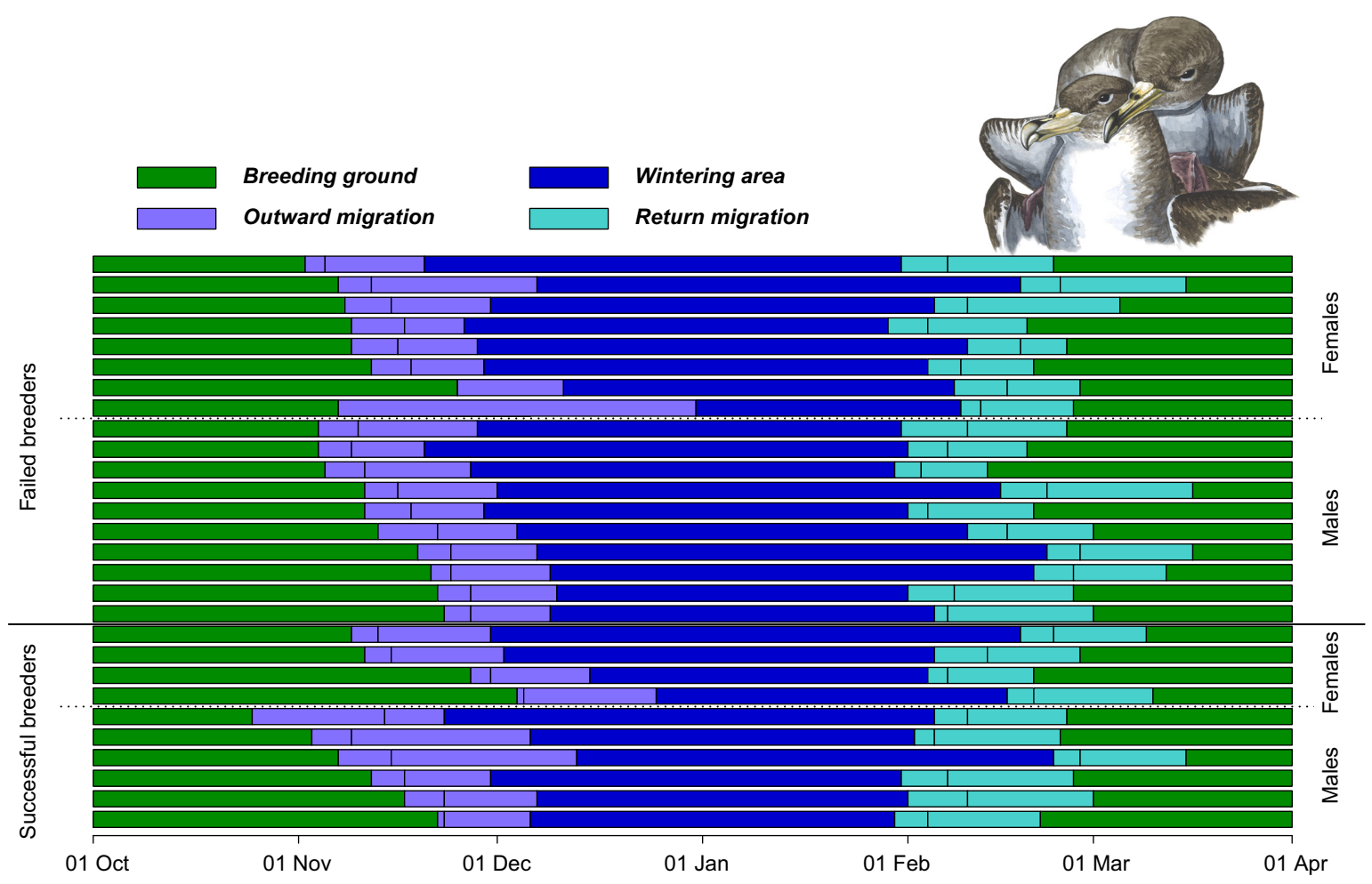

FIG. 2. Phenological schedules of failed (18 individuals) and successful (10 individuals) breeders of Cory's shearwaters that undertook long-distance migrations (i.e., migratory birds). Individuals are organized by treatment group (split by a continuous line) and sex (split by dotted lines). Main phenological events are plotted in different colors: staging in the breeding ground in green, outward (autumn) migration in light purple, wintering period in dark purple, and return migration in cyan blue. Additionally, middle lines in both migration periods indicate crossing of the $10^{\circ} \mathrm{N}$ parallel. None of the date limits between phenological events differed statistically.

distribution of error terms and a log-link function were used in the modeling. The best-supported models were selected using the Akaike's information criteria corrected for small sample sizes $\left(\mathrm{AIC}_{\mathrm{c}}\right)$ and the corresponding $\mathrm{AIC}_{\mathrm{c}}$ weights (Johnson and Omland 2004). GLMMs were conducted in R version 2.8.1 ( $\mathrm{R}$ Development Core Team 2017) with additional functions provided by the $\mathrm{R}$ packages lme4 (lmer; Bates et al. 2017) and MuMIn (dredge; Bartoń 2017).

\section{SIA procedures and isotopic interpolation}

Basal portions of primary feathers were washed in a $0.25 \mathrm{~mol} / \mathrm{L}$ sodium hydroxide solution $(\mathrm{NaOH})$, rinsed twice thoroughly in distilled water to remove any surface contamination and dried in an oven at $40^{\circ} \mathrm{C}$ to constant mass. They were cut with scissors to a fine powder to homogenize every sample. Subsamples of powdered feathers were weighed to the nearest microgram, placed in tin capsules and crimped for combustion for $\mathrm{C}, \mathrm{N}$ and $\mathrm{S}$ isotope determinations. SIA was carried out at the Serveis Científico-Tècnics of the Universitat de Barcelona (SCTUB; Spain) by means of elemental analysis-isotope ratio mass spectrometry using a ThermoFinnigan Flash 1112 (CE Elantech, Lakewood, New Jersey, USA) elemental analyzer coupled to a Delta-C isotope ratio mass spectrometer via a CONFLOIII interface (ThermoFinnigan MAT, Bremen, Germany). Stable isotope ratios were expressed in the standard $\delta$-notation $(\%$ ) relative to Vienna Pee Dee Belemnite (VPDB; $\left.\delta^{13} \mathrm{C}\right)$, atmospheric $\mathrm{N}_{2}\left(\mathrm{AIR} ; \delta^{15} \mathrm{~N}\right)$ and Vienna-
Canyon Diablo Troilite (VCDT; $\delta^{34} \mathrm{~S}$ ). The isotopic ratio mass spectrometry facility at the SCT-UB applies international inorganic standards (IAEA $\mathrm{CH}_{7}$, IAEA $\mathrm{CH}_{6}$ and USGS-24 for C, IAEA $\mathrm{N}_{1}$, IAEA $\mathrm{N}_{2}$ and IAEA $\mathrm{NO}_{3}$ for $\mathrm{N}$ and IAEA-S1, IAEA-S2, IAEA-S3, NBS-127 and YCEM for $\mathrm{S}$ ) inserted every 12 samples to calibrate the system and compensate for any drift over time. Replicate assays of standard materials indicated measurement errors of $\pm 0.1 \%$, $\pm 0.2 \%$ and $\pm 0.2 \%$, for $\mathrm{C}, \mathrm{N}$ and $\mathrm{S}$, respectively, but these are likely underestimates of true measurement error for complex organics like feathers.

First, to assess whether isotopic feather composition could be linked to specific oceanic areas, we evaluated differences in $\delta^{13} \mathrm{C}, \delta^{15} \mathrm{~N}$ and $\delta^{34} \mathrm{~S}$ of those feathers that are known to be molted in the wintering grounds, i.e., P9 feathers (Ramos et al. 2009b). As isotopic data of P9s did not deviate from normal distribution (Shapiro-Wilk test), we used parametric comparisons (including one-way ANOVA and Tukey-tests for pair-comparisons; Appendix S1: Table S2) to assess isotopic differences/similarities among the seven non-breeding destinations that we defined from geolocation data. This analysis unraveled those wintering areas that were isotopically distinct (Appendix S1: Fig. S2), and that could be used in the subsequent discriminant analysis. For this analysis, P9 feathers of pseudo-resident birds were assigned to the Canary Current, as those from resident birds. Second, to illustrate isotopic changes along wing molt, we modeled (using GAMMs) the three isotopic values including treatment and non-breeding destination (i.e., those 


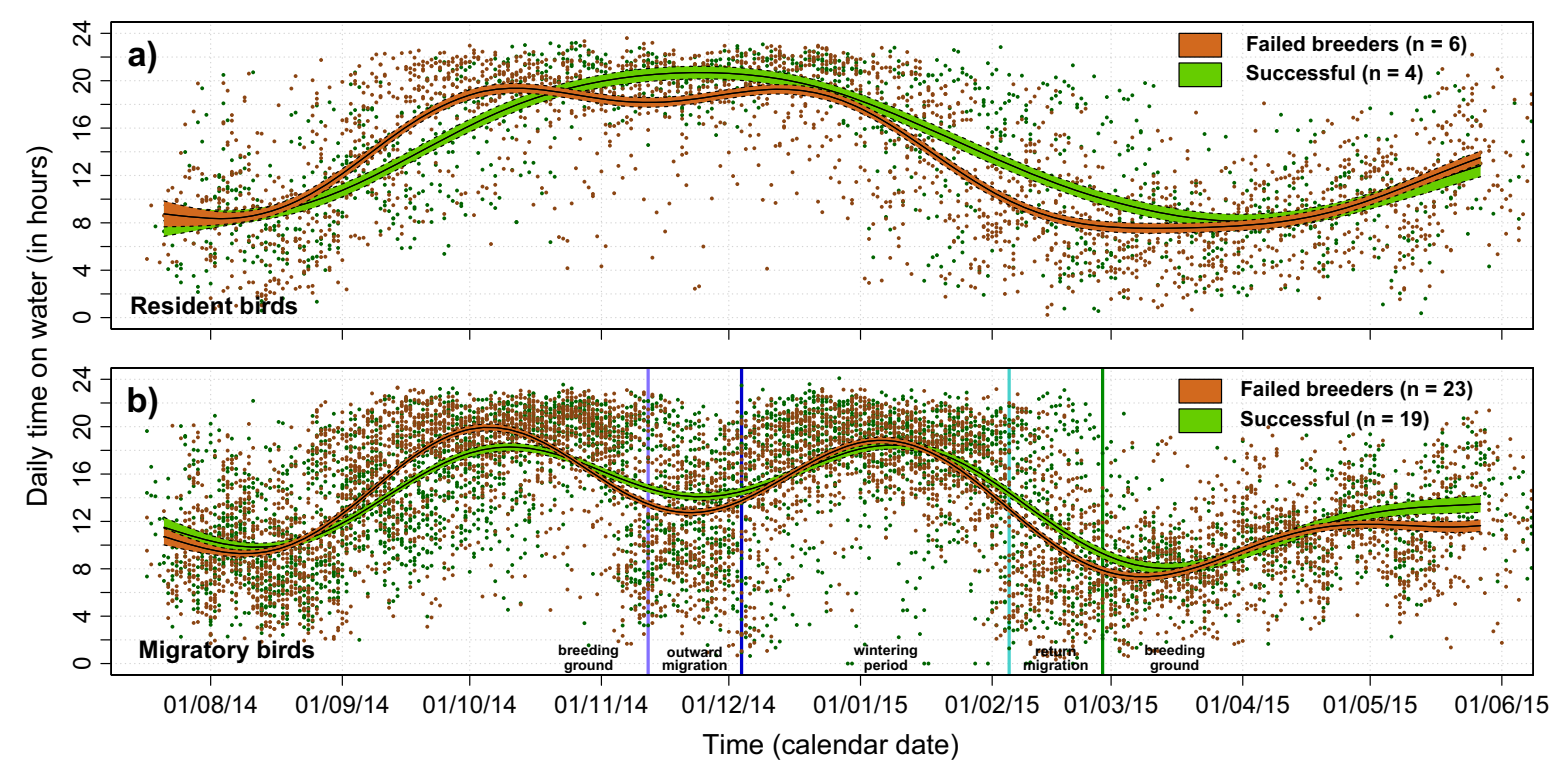

FIG. 3. Daily resting time year-round for the two migratory strategies we defined: (a) resident and (b) migratory birds. Estimates of daily time on the water (in hours) are modeled and plotted separately for both treatment groups: failed breeders in brown, and successful breeders in green. The solid lines correspond to the mean for each treatment group estimated using generalized additive mixed models, and the colored regions around the means delimited by dashed lines represent the associated 95\% CI of the slopes. As reference, colored lines in (b) correspond to average dates of starting the main phenological events estimated for migratory birds: outward (autumn) migration (in light purple), wintering period (dark purple), return migration (cyan blue), and staging in the breeding ground (green).

three molting areas that became isotopically distinct in previous analyses, see Results; Appendix S1: Fig. S2) as fixed factors, feather type (P1, P3, P5, P7, and P9, sequentially) as a smooth term, and bird identity as a random term (Fig. 4). Finally, we performed a Linear Discriminant function Analysis (LDA) to classify every wing feather according to the place it presumably grew. We constructed the LDA with the three isotopic signatures of P9 feathers, and proposing only those three molting areas that became isotopically distinct in previous analysis (see Results; Appendix S1: Fig. S3). LDA was conducted using the function lda in R, and models were cross-validated using jack-knife procedures. Gaussian bivariate ellipses were calculated as $95 \%$ probability interval of the mean of the two Linear Discriminant functions (LD) for each of the three molting areas with the package SIBER (Jackson et al. 2011). Finally, we tested for different proportions of molting grounds between treatments for each specific feather $\left(\chi^{2}\right.$; Table 6$)$.

\section{Corticosterone determination}

CORT concentrations in breeding and non-breeding feathers (P1 and S13, respectively) were assessed through competitive EIA kits (Corticosterone ELISA kit; Neogen ${ }^{\circledR}$ Corporation, Ayr, UK), following an optimized protocol described elsewhere (Carbajal et al. 2014). Briefly, after discarding the calamus (Bortolotti et al. 2008), feathers were minced with a ball-mill (Retsch ${ }^{\circledR}$, MM2 type, Haan, Germany) for $5 \mathrm{~min}$ at $25 \mathrm{~Hz}$. Then, $1.5 \mathrm{~mL}$ of methanol (methanol reagent grade 99.9\%; Scharlab, Sentmenat, Spain) was added and samples were placed in a vortex (Vortex Mixer S0200-230 V-EU; Labnet International, Edison, New Jersey, USA) for $30 \mathrm{~min}$ at room temperature, followed by incubation at $32^{\circ} \mathrm{C}$ for $18 \mathrm{~h}$ (G24 Environmental Incubator Shaker;
New Brunswick Scientific, Edison, New Jersey, USA) for steroid extraction. Samples were centrifuged (Hermle Z300K; Hermle ${ }^{\circledR}$ Labortechnik, Wehingen, Germany) at 4,050 $\times g$ at $25^{\circ} \mathrm{C}$ for $15 \mathrm{~min}$ and $1 \mathrm{~mL}$ of supernatant was transferred to a new aliquot. Samples were then placed in an oven at $37.5^{\circ} \mathrm{C}$ until dry. Dried extracts were reconstituted with $0.25 \mathrm{~mL}$ of EIA buffer provided by the EIA kit, shaken for $1 \mathrm{~min}$, and immediately stored at $-20^{\circ} \mathrm{C}$ until analysis. Simultaneously, 25 samples were pooled to biochemically validate the immunoassay, following the essential criteria (Sink et al. 2008). Intra- and inter-assay coefficients of variation were $4.7 \%$ and $12.3 \%$, respectively. Regarding the dilution test, the efficiency of CORT extraction was $91.2 \% \pm 8.4 \%$ with an $R^{2}$ of $99.0 \%$. The average recovery percentage from spike-and-recovery test was $101.0 \% \pm 19.8 \%$. Pooled samples showed parallel displacement with the standard curve (standard curve: $y=0.28 x-1.56, R^{2}=0.94$; pool feather samples curve: $y=0.28 x-0.49, \quad R^{2}=0.99 ; \quad$ correlation: $R^{2}=0.98, P$-value $\left.<0.001\right)$. All samples were above the detection limit $(0.20 \mathrm{pg} / \mathrm{mm})$.

After evaluating the normality of the distributions of CORT values, we performed Linear Mixed Models (LMMs) to analyze CORT values in feathers. We built a set of competing models, considering treatment, feather type (i.e., P1 or S13), migratory strategy, and sex as fixed factors, and bird identity as a random effect to account for the dependence among feathers of the same individual (Table 7). We included sex because CORT levels of males and females are known to differ within the same season in several seabird species (Pérez et al. 2016). The full model included all fixed factors and double interactions. We selected the most parsimonious models based on $\mathrm{AIC}_{\mathrm{c}}$ values: $\triangle \mathrm{AIC}_{\mathrm{c}}$ between the two best models was lower than 2 (Johnson and Omland 2004), and we therefore performed model averaging using 
a)

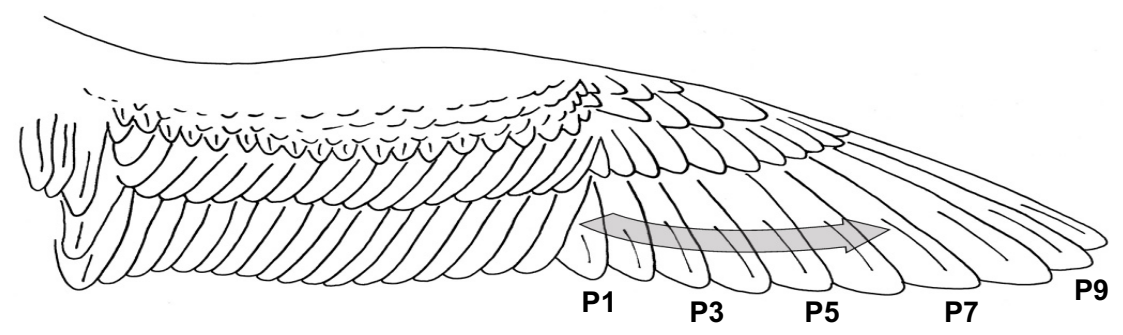

b)
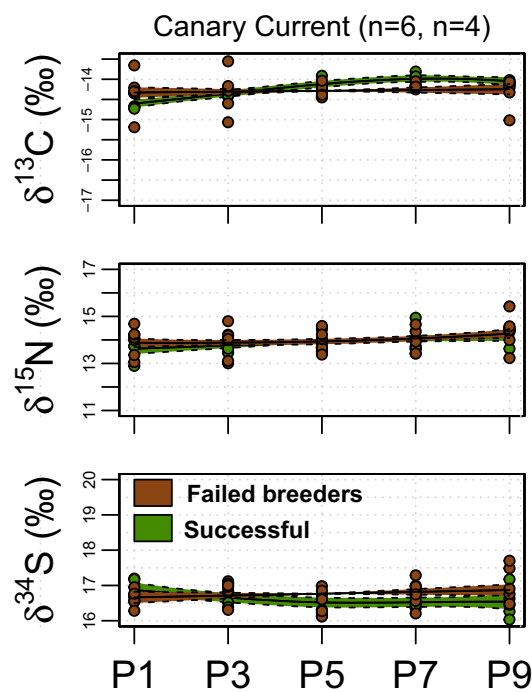

Angola \& Benguela $(n=21, n=17)$
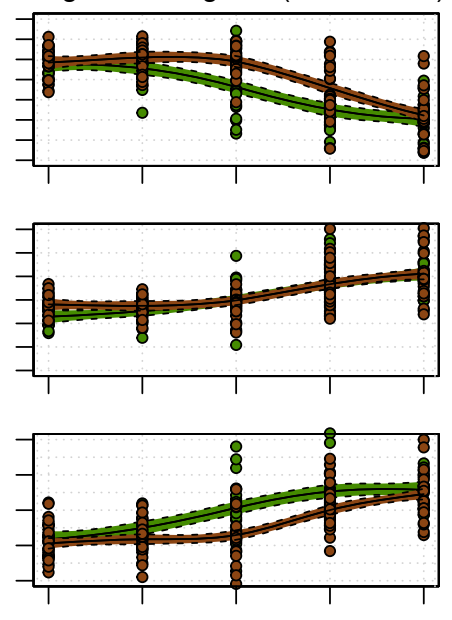

P1 P3 $\quad$ P5 $\quad$ P7 $\quad$ P9
Brazil \& Agulhas $(n=3, n=3)$
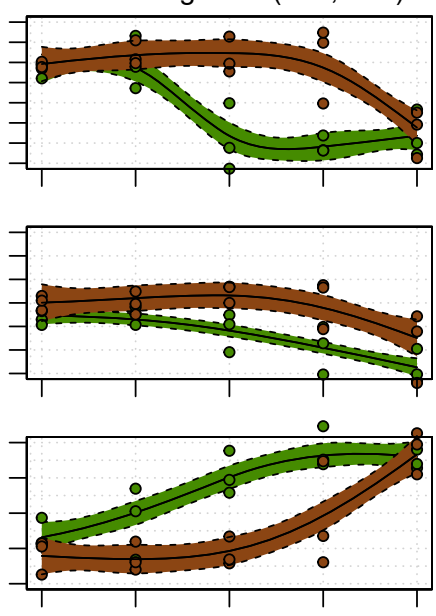

P1 1 P3 $\quad$ P5 $\quad$ P7 $\quad$ P9

\section{Primary feather}

FIG. 4. Cory's shearwater wing scheme with selected primary feathers analyzed for stable isotope analysis (a). Primary molt pattern is shown by the grey arrow (Ramos et al. $2009 b)$. Carbon $\left(\delta^{13} \mathrm{C}\right)$, nitrogen $\left(\delta^{15} \mathrm{~N}\right)$ and sulfur $\left(\delta^{34} \mathrm{~S}\right)$ isotopic values were modeled (GAMMs) along the primary molt sequence, i.e., along the 1st, 3rd, 5th, 7th and 9th primary feathers (P1, P3, P5, P7 and P9, respectively) for each of the isotopic areas we defined (Appendix S1: Table S2) (b). These three isotopically similar areas were: (1) Canary Current, (2) Angola, Benguela, Benguela-Agulhas confluence and South Central Atlantic regions, and (3) Brazil and Agulhas Currents. Failed and successful breeders are depicted separately (sample sizes in brackets), in brown and green, respectively.

the function model.avg (Barton 2017) of those two models to obtain statistical estimates for our variables.

\section{RESULTS}

Spatial distribution, migration characteristics, phenology, and subsequent breeding performance

As previously described for the species (González-Solís et al. 2007, Dias et al. 2011), most of our study birds (75\%) undertook a long-distance, trans-equatorial migration from their breeding grounds (i.e., in the Canary Current) to their main wintering grounds in the South Atlantic (Table 2). Main wintering sites for the studied population included, in order of relevance, the Benguela, Agulhas (in the Indian Ocean), Angola, and Brazil Currents, as well as the south central Atlantic (Fig. 1; Appendix S1: Table S2). However, a relevant proportion of birds $(25 \%)$ also stayed around the Canary Current for wintering (Table 2). Interestingly, although essentially resident, some of these birds undertook a long-distance short trip (of less than $15 \mathrm{~d}$ on average) at the end of the non-breeding period, perhaps reflecting a sort of a migratory restlessness. Migratory strategy did not differ between treatment groups $\left(\chi^{2}=0.03, \mathrm{df}=1, P\right.$-value $=$ 0.859; Table 2), and both failed and successful breeders undertook long-distance migrations in similar proportions (73.3 and 79.2, respectively).

Phenological parameters did not differ between treatment groups, nor did it differ between sexes (Table 3 and Fig. 2). Parameters estimated for long-distance migratory birds were similar for failed and successful breeders (Fig. 2). Only when considering activity data from all birds (both resident and migratory), the last night in the burrow showed a slight trend to be significantly delayed in successful breeders by two weeks $\left(F_{1,46}=3.0, P\right.$-value $=0.088$; Table 3$)$.

Breeding success on the subsequent breeding attempt (i.e., in 2015) did not differ between treatment groups $\left(\chi^{2}=0.0\right.$, $\mathrm{df}=1, P$-value $=0.999$; Table 4$)$, even when analyzing males and females separately to avoid pseudo-replication of breeding success from the same pair (males: $\chi^{2}=0.0, \mathrm{df}=1$, $P$-value $=0.999$; females: $\chi^{2}=0.0, \mathrm{df}=1, P$-value $\left.=0.999\right)$.

\section{At-sea activity patterns}

We obtained activity data from all loggers included in the spatial analysis. At-sea activity patterns revealed substantial 
TABLE 4. Breeding success of the individuals included in the experiment in 2014 and in their subsequent breeding attempt, in 2015, split by sex.

\begin{tabular}{lcccccccc}
\hline \hline & \multicolumn{3}{c}{$\begin{array}{c}\text { Induced failure in } \\
2014\end{array}$} & & \multicolumn{3}{c}{$\begin{array}{c}\text { Successful in } \\
2014\end{array}$} \\
\cline { 2 - 4 } \cline { 7 - 9 } Breeding success & Males & Females & All & & Males & Females & All \\
\hline Failed in 2015 & 7 & 5 & 12 & & 5 & 5 & 10 \\
Successful in 2015 & 7 & 6 & 13 & & 6 & 6 & 12
\end{tabular}

Note: Notice that a few individuals skipped breeding in 2015, and therefore the sample size is smaller than in Table 2.

heterogeneity among the migratory strategies we defined, particularly during the non-breeding season (Fig. 3). First, resident and migratory birds displayed some similarities in activity patterns: birds spent more daily time flying during the breeding season than during the non-breeding season, when most shearwaters spent much of their daily time resting on the water (Fig. 3). However, different patterns can be observed between the two migratory strategies. While resident birds rested equally throughout the non-breeding period, migratory birds displayed a sinusoidal shape in their activity profile throughout the non-breeding period, clearly reflecting the post-nuptial migration they undertook in midlate November (Fig. 3).

Statistical differences were measured between the treatment groups when considering specific months, such as those affecting the late breeding period and the pre-breeding period of the following breeding season (i.e., September 2014 and February 2015, respectively; Table 5; Appendix S1: Fig. S1). Based on AIC values, the best-supported models of the daily activity for such specific months included treatment group as a fixed effect (Table 5). In addition, individual accounted for a relevant proportion of the total variability in both cases. On average, failed breeders spent more time on the water (about one hour) in the post-breeding period than successful breeders, and the reverse was true in February, during the pre-breeding period, when failed breeders rested less time on the water (three hours; Table 5).

\section{Stable isotope analysis and geographic assignment}

First, we assessed potential isotopic differences among wintering grounds (as indicated by the geolocators) using the isotopic signatures of those feathers molted in winter (i.e., P9s). Based on pair-comparisons of the three isotopic values of those feathers (Tukey-tests; Appendix S1: Table S2 and Fig. S2), we combined wintering sites with similar values as follows: (1) Canary, (2) Angola, Benguela, BenguelaAgulhas confluence and South Central Atlantic, and (3) Brazil and Agulhas Currents. These three "isotopic areas" showed distinct isotopic values (Fig. 4) that were used in the LDA to ultimately assign the molting site of every flight feather to the breeding or the non-breeding ground.

The sequential molt pattern expressed in the $\delta^{13} \mathrm{C}, \delta^{15} \mathrm{~N}$ and $\delta^{34} \mathrm{~S}$ values of primary feathers revealed two expected patterns (Fig. 4): (1) resident birds molted all primaries in the same area (i.e., the Canary Current), while migratory individuals showed primary feathers with two different isotopic profiles; and more interestingly, (2) assuming P1 represents the isotopic values of the feathers molted at the breeding grounds, failed breeders tended to replace more feathers at the breeding grounds (i.e., the Canary Current isotopic area) than successful breeders.

The LDA based on the three isotopic signatures of P9 feathers showed a high percentage of correct assignment

TABLE 5. Generalized linear mixed models (GLMMs) testing for the effect of treatment group (induced failure vs. successful breeders) and migration strategy (resident vs. migratory birds) on daily activity budget in September and February, separately. (a) Candidate models evaluated to fit the data corresponding to daily activity budget (in hours) and their associated measures of information ( $\mathrm{AIC}_{\mathrm{c}}$ : corrected Akaike's information criterion; $\triangle \mathrm{AIC}_{\mathrm{c}}$ : $\mathrm{AIC}_{\mathrm{c}}$ increments and $\mathrm{AIC}_{\mathrm{c}} \mathrm{Wgt}$ : $\mathrm{AIC}_{\mathrm{c}}$ weights). The most complete model included treatment group and migration strategy factors, as well as their interaction. All evaluated models included bird identity as a random factor. The best-supported models are shown in bold. (b) Parameter estimates ( \pm standard error, SE) from the best-supported models and their significance.

\begin{tabular}{|c|c|c|c|c|c|c|c|}
\hline & \multirow[b]{3}{*}{$k$} & \multicolumn{6}{|c|}{ Daily time on the water (in hours) } \\
\hline & & \multicolumn{3}{|c|}{ September } & \multicolumn{3}{|c|}{ February } \\
\hline & & $\mathrm{AIC}_{\mathrm{c}}$ & $\Delta \mathrm{AIC}_{\mathrm{c}}$ & $\mathrm{AIC}_{\mathrm{c}} \mathrm{Wgt}$ & $\mathrm{AIC}_{\mathrm{c}}$ & $\Delta \mathrm{AIC}_{\mathrm{c}}$ & $\mathrm{AIC}_{\mathrm{c}} \mathrm{Wgt}$ \\
\hline \multicolumn{8}{|l|}{ (a) } \\
\hline Treatment $\times$ Migratory.strategy & 6 & 8130.2 & 3.06 & 0.121 & 6582.5 & 6.58 & 0.029 \\
\hline Treatment + Migratory.strategy & 5 & 8129.5 & 2.36 & 0.283 & 6579.2 & 3.35 & 0.144 \\
\hline Treatment & 4 & 8127.1 & 0.00 & 0.000 & 6575.9 & 0.00 & 0.769 \\
\hline Migratory.strategy & 4 & 8135.0 & 7.87 & 0.011 & 6584.5 & 8.62 & 0.010 \\
\hline Constant & 3 & 8133.3 & 6.18 & 0.025 & 6581.4 & 5.56 & 0.048 \\
\hline
\end{tabular}

(b)

\begin{tabular}{|c|c|c|c|c|c|c|}
\hline Fixed effects & Estimate $\pm \mathbf{S E}$ & $t$ value & $P$-value & Estimate $\pm \mathbf{S E}$ & $t$ value & $P$-value \\
\hline Induced failure & $13.1 \pm 0.4$ & 34.0 & $<0.001$ & $9.6 \pm 0.8$ & 13.2 & $<0.001$ \\
\hline Successful & $12.3 \pm 0.4$ & 28.3 & $<0.001$ & $12.8 \pm 0.8$ & 15.5 & $<0.001$ \\
\hline Random effects & \multicolumn{2}{|c|}{ Variance \pm SD } & \multicolumn{4}{|c|}{ Variance \pm SD } \\
\hline Individual & \multicolumn{2}{|c|}{$3.9 \pm 2.0$} & \multicolumn{4}{|c|}{$13.4 \pm 3.7$} \\
\hline Residual & \multicolumn{2}{|c|}{$24.3 \pm 4.9$} & \multicolumn{4}{|c|}{$18.3 \pm 4.3$} \\
\hline
\end{tabular}


(94.4\%) to the respective non-breeding area where they were molted (as assessed from the geolocation light data; Appendix S1: Fig. S3e). The first LD (LD1) accounted for $74.0 \%$ of variance, while the second LD (LD2) retained the remaining $26.0 \%$ of among-group variance (Appendix S1: Fig. S3). The LDA revealed that all P1s and most P3s were molted in the Canary Current isotopic area, while the molting of $\mathrm{P} 5 \mathrm{~s}, \mathrm{P} 7 \mathrm{~s}$ and $\mathrm{P} 9 \mathrm{~s}$ was distributed along the three isotopic areas we defined (Table 6; Appendix S1: Fig. S3). Interestingly, differences between the treatment groups in the proportions of assignment to molting areas were only found in P5s and P7s (Table 6).

\section{Corticosterone levels}

Two GLMMs were equally parsimonious in explaining CORT data $\left(\triangle \mathrm{AIC}_{\mathrm{c}}<2\right)$ and, therefore, we performed model averaging between them (Table 7). Both models retained treatment group (failed and successful breeders) and feather type (P1 and S13) as relevant explanatory factors. CORT levels were higher in successful breeders and when considering P1 feathers (Fig. 5). Although CORT levels did not differ between sexes, males tended to have higher values, independent of their breeding success and the feather we analyzed (Table 7).

\section{DisCUSSION}

Carryover effects of raising offspring successfully from the breeding to the non-breeding period, such as phenological events, have largely relied on observations and inferences from correlations (Mitchell et al. 2012). Here, by reducing the parental effort of Cory's shearwaters, we provide experimental evidence of how the costs of breeding effort could carryover from the breeding to the non-breeding period through changes in molting strategies and CORT levels. Interestingly, we did not find any evidence that a decrease in the breeding effort actually influenced migratory behavior or the subsequent breeding attempts, suggesting that costs of breeding may be rapidly buffered during the post-breeding period, as would be expected in a long-lived species in the context of the life history theory.

\section{Carryover effects of breeding on molting schedules}

Traditionally, in birds, breeding, flight feather molt and migration have been considered to be incompatible processes, as they are all highly energy-demanding activities, and therefore, they are usually segregated over time (Bridge 2006, Barta et al. 2008). We constructed the LDA with the three isotopic signatures of $\mathrm{P} 9$ feathers, and proposing only those three moulting areas that became isotopically distinct in previous analysis (see Results; Appendix S1: Fig. S3). Based on direct observation of birds at the breeding colony or animals found dead, it is known that in Cory's shearwaters the onset of the molt of primary feathers overlaps with the end of the breeding season (Alonso et al. 2009, Ramos et al. 2009b). That is, Cory's shearwaters normally molt the innermost one to four primary feathers during the late chickrearing period (Ramos et al. 2009b), suspend the molt for migrating, and renew it to replace the rest of the flight feathers in the wintering grounds before the pre-nuptial migration (Monteiro and Furness 1996, Ramos et al. 2009a). In some species, general molting strategies can also be inferred from the activity data obtained from geolocators (Cherel et al. 2016). The molting pattern of Cory's shearwaters described above is consistent with the flying activity of migratory animals recorded throughout the breeding and non-breeding periods (Fig. 3b). Birds maintained a balance between resting and flying activity along the early and mid-breeding season, as well as during both migration periods, but they spent most of their time resting on the water both at the end of the breeding season and during the wintering season (around 1st October and 1st January, respectively). These results are further supported by SIA on the sequence of the sampled primary feathers (Fig. 4): in migrating Cory's shearwaters, the innermost primaries (i.e., P1 and P3) showed similar isotopic values and therefore were molted and regrown at the breeding grounds, while the most distal primaries (P7 and P9) showed a shift of their values in relation to the innermost

TABLE 6. Linear discriminant function analysis (LDA) results that classified different primary feathers (P1, P3, P5, P7, and P9) according to the place they presumably grew (among those three molting areas that unraveled as isotopically distinct; see Appendix S1: Table S2).

\begin{tabular}{|c|c|c|c|c|c|c|}
\hline \multirow[b]{2}{*}{$\begin{array}{l}\text { Primary } \\
\text { feather }\end{array}$} & \multirow[b]{2}{*}{ Treatment } & \multicolumn{3}{|c|}{ Wintering area } & \multirow[b]{2}{*}{$\chi^{2}$} & \multirow[b]{2}{*}{$P$-value } \\
\hline & & $\begin{array}{l}\text { Canary } \\
\text { Current }\end{array}$ & $\begin{array}{c}\text { Angola, Benguela, Confluence } \\
\text { Benguela-Agulhas, South } \\
\text { Central Atlantic } \\
\end{array}$ & $\begin{array}{c}\text { Brazil and } \\
\text { Agulhas Currents }\end{array}$ & & \\
\hline \multirow[t]{2}{*}{$\mathrm{P} 1$} & Induced failure & 30 & 0 & 0 & & \\
\hline & Successful & 24 & 0 & 0 & 2.31 & 0.315 \\
\hline \multirow[t]{2}{*}{ P3 } & Induced failure & 30 & 0 & 0 & & \\
\hline & Successful & 21 & 1 & 2 & 3.97 & 0.137 \\
\hline \multirow[t]{2}{*}{ P5 } & Induced failure & 29 & 1 & 0 & & \\
\hline & Successful & 11 & 6 & 7 & 18.23 & $<0.001$ \\
\hline \multirow[t]{2}{*}{ P7 } & Induced failure & 16 & 13 & 1 & & \\
\hline & Successful & 5 & 14 & 5 & 7.90 & 0.019 \\
\hline \multirow[t]{2}{*}{ P9 } & Induced failure & 8 & 18 & 4 & & \\
\hline & Successful & 4 & 17 & 3 & 0.85 & 0.654 \\
\hline
\end{tabular}

Notes: The LDA was based on $\delta^{13} \mathrm{C}, \delta^{15} \mathrm{~N}$ and $\delta^{34} \mathrm{~S}$ values of P9 feathers, i.e., those feathers molted in the wintering grounds. Notice that P9 assignments revealed $94.4 \%$ correct classification. Additionally, specific $\chi^{2}$ tests performed for each feather were carried out to evaluate potential differences in the molting areas between the treatment groups (failed and successful breeders). 
TABLE 7. Generalized Linear Mixed Models (GLMMs) testing for the effect of treatment group (induced failure vs. successful breeders), sampled feather (1st primary [P1], 13th secondary feather [S13]), migration strategy (resident vs. migratory birds) and sex (male, female) on corticosterone (CORT) concentration evaluated in feathers (pg of CORT/mm of feather). (a) Candidate models evaluated to fit the data corresponding to CORT levels in feathers and their associated measures of information ( $\mathrm{AIC}_{\mathrm{c}}$ : corrected Akaike's Information Criterion; $\triangle \mathrm{AIC}_{\mathrm{c}}$ : $\mathrm{AIC}_{\mathrm{c}}$ increments and $\mathrm{AIC}_{\mathrm{c}} \mathrm{Wgt}$ : $\mathrm{AIC}_{\mathrm{c}}$ weights). The most complete model included treatment, feather, migration strategy (as 'migratory') and sex factors, as well as treatment $\times$ feather, treatment $\times$ migratory and treatment $\times$ sex interactions. All evaluated models included bird identity as a random factor. The two best-supported models are shown in bold. (b) Parameter estimates ( \pm standard error, SE) of the average (conditional) model from the two best-supported models, as well as their significance.

\begin{tabular}{|c|c|c|c|c|}
\hline & \multirow[b]{2}{*}{$k$} & \multicolumn{3}{|c|}{$\mathrm{pg}$ CORT $/ \mathrm{mm}$ feather } \\
\hline & & $\mathrm{AIC}_{\mathrm{c}}$ & $\Delta \mathrm{AIC}_{\mathrm{c}}$ & $\mathrm{AIC}_{\mathrm{c}} \mathrm{Wgt}$ \\
\hline \multicolumn{5}{|l|}{ (a) } \\
\hline Treatment $\times$ Feather $\times$ Migratory $\times$ Sex & 10 & 528.0 & 9.41 & 0.003 \\
\hline Treatment + Feather $\times$ Migratory $\times$ Sex & 9 & 525.5 & 6.98 & 0.009 \\
\hline Treatment $\times$ Feather $\times$ Migratory + Sex & 9 & 526.0 & 7.50 & 0.007 \\
\hline Treatment $\times$ Feather + Migratory $\times$ Sex & 9 & 526.2 & 7.68 & 0.006 \\
\hline Treatment + Feather $\times$ Migratory + Sex & 8 & 523.7 & 5.12 & 0.022 \\
\hline Treatment + Feather + Migratory $\times$ Sex & 8 & 523.8 & 5.30 & 0.020 \\
\hline Treatment $\times$ Feather $\times$ Sex & 8 & 523.9 & 5.38 & 0.019 \\
\hline Treatment $\times$ Feather + Migratory + Sex & 8 & 524.2 & 5.62 & 0.017 \\
\hline Treatment $\times$ Feather $\times$ Migratory & 8 & 524.6 & 6.02 & 0.014 \\
\hline Treatment $\times$ Migratory $\times$ Sex & 8 & 557.0 & 38.47 & 0.000 \\
\hline Treatment + Feather $\times$ Sex & 7 & 521.6 & 3.05 & 0.061 \\
\hline Treatment + Feather + Migratory + Sex & 7 & 521.8 & 3.29 & 0.054 \\
\hline Treatment $\times$ Feather + Sex & 7 & 521.9 & 3.34 & 0.053 \\
\hline Treatment + Feather $\times$ Migratory & 7 & 522.2 & 3.69 & 0.044 \\
\hline Treatment $\times$ Feather + Migratory & 7 & 522.9 & 4.34 & 0.032 \\
\hline Treatment $\times$ Migratory + Sex & 7 & 555.2 & 36.64 & 0.000 \\
\hline Treatment + Migratory $\times$ Sex & 7 & 555.4 & 36.84 & 0.000 \\
\hline Treatment + Feather + Sex & 6 & 519.6 & 1.06 & 0.164 \\
\hline Treatment + Feather + Migratory & 6 & 520.6 & 2.06 & 0.100 \\
\hline Treatment $\times$ Feather & 6 & 520.8 & 2.23 & 0.091 \\
\hline Feather + Migratory + Sex & 6 & 530.7 & 12.13 & 0.001 \\
\hline Treatment $\times$ Sex & 6 & 553.2 & 34.63 & 0.000 \\
\hline Treatment + Migratory $\times$ Sex & 6 & 553.4 & 34.87 & 0.000 \\
\hline Treatment $\times$ Migratory & 6 & 553.8 & 35.23 & 0.000 \\
\hline Treatment + Feather & 5 & 518.5 & 0.00 & 0.279 \\
\hline Feather + Sex & 5 & 528.4 & 9.88 & 0.002 \\
\hline Feather + Migratory & 5 & 529.1 & 10.57 & 0.001 \\
\hline Treatment + Sex & 5 & 551.2 & 32.68 & 0.000 \\
\hline Treatment + Migratory & 5 & 552.2 & 33.64 & 0.000 \\
\hline Migratory + Sex & 5 & 562.5 & 43.92 & 0.000 \\
\hline Feather & 4 & 526.9 & 8.39 & 0.004 \\
\hline Treatment & 4 & 550.2 & 31.62 & 0.000 \\
\hline Sex & 4 & 560.3 & 41.72 & 0.000 \\
\hline Migratory & 4 & 560.9 & 42.38 & 0.000 \\
\hline Constant & 3 & 558.8 & 40.24 & 0.000 \\
\hline
\end{tabular}

(b)

\begin{tabular}{lrr}
\hline Fixed effects & Estimate \pm SE & $P$-value \\
\hline Failed breeder, P1, Female (Intercept) & $11.9 \pm 0.6$ & $<0.001$ \\
Successful breeder & $2.2 \pm 0.6$ & $<0.001$ \\
S13 & $-3.2 \pm 0.5$ & $<0.001$ \\
Male & $0.6 \pm 0.6$ & 0.303 \\
\hline Random effect & Variance \pm SD \\
\hline Individual & $2.4 \pm 1.6$ & \\
Residual & $5.6 \pm 2.4$ & \\
\hline
\end{tabular}

primaries, indicating that these feathers were replaced at the wintering grounds. The isotopic shift between the innermost and the outermost primary feathers in Cory's shearwaters has been previously found in other studies (Ramos et al. 2009a) and is dependent on the basal isotopic signatures of each isotope at each wintering area. This clearly suggested a spatial segregation in the molting patterns of the species, with two main molting areas for those migratory individuals. 

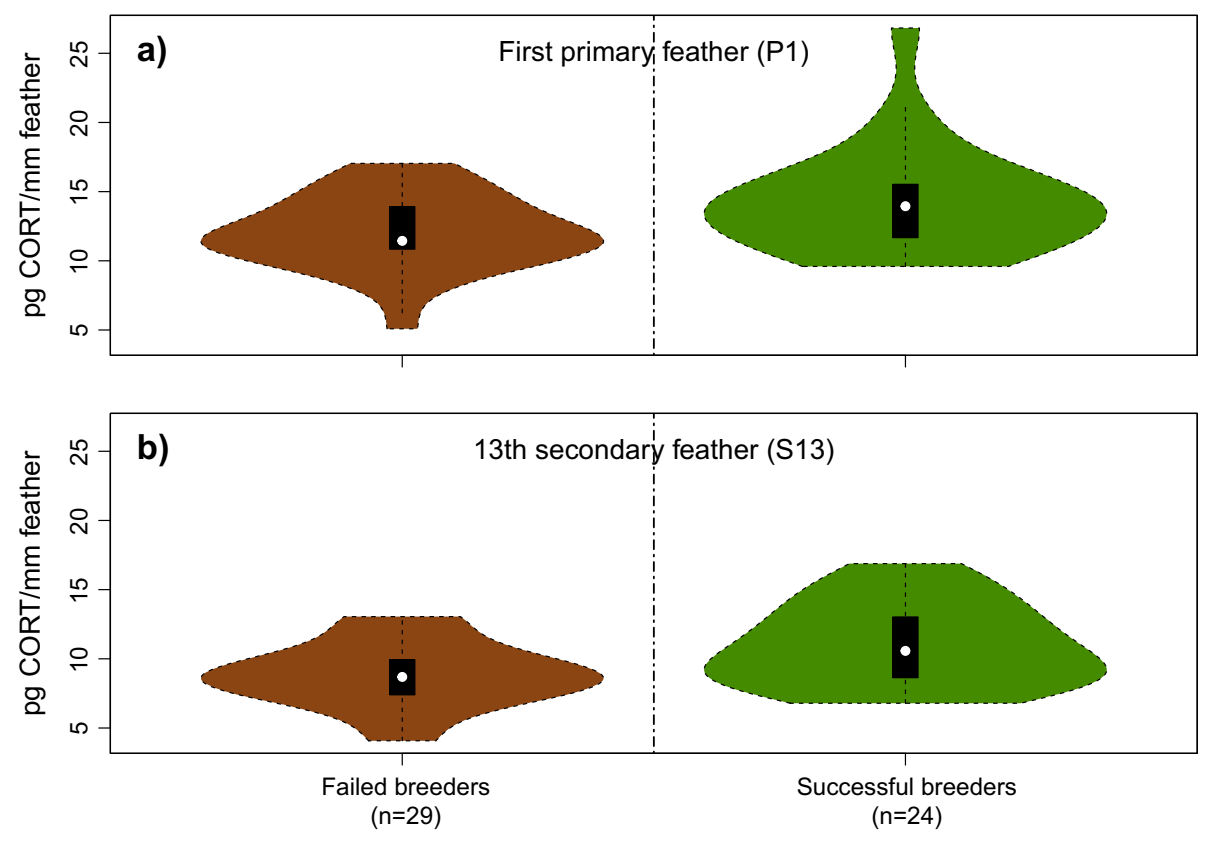

FIG. 5. Corticosterone levels in (a) breeding and (b) non-breeding feathers (1st primary feather, P1, and 13th secondary feather, S13, respectively) of individuals in relation to the treatment group. Numbers below each $X$-axis caption represent sample sizes of each group.

Beyond the general patterns of change in flight activity and isotopic signatures through the molt sequence, we could also detect some differences between failed and successful breeders. Failed breeders spent more time on the water at the end of the breeding season (i.e., September) than successful breeders. This increase in the resting time of failed breeders may reflect a better body condition at the end of the breeding period, and thus a lower energetic demand that ultimately conditions foraging activity (Daunt et al. 2006, Fayet et al. 2016). Alternatively, this could be a result of flight impairment due to an advance in their molt schedule (Cherel et al. 2016). Indeed, SIA results is consistent with the latter hypothesis, since failed breeders molted more primary feathers (e.g., up to P5) in the breeding grounds than successful breeders. This, in addition to the fact that no difference in outward migration timing was observed between groups (see previous paragraph), confirmed that failed breeders certainly advance their molt while do not migrate earlier. Interestingly, our study also provided strong evidence that this advancement in molt persisted and had consequences during the non-breeding period. Our failed breeders replaced fewer feathers in the wintering grounds, and therefore, they may have more time at the end of the wintering period (i.e., in February) for foraging and accumulating more reserves while still staying in the wintering grounds (Table 5).

Daily activity budgets of Cory's shearwaters could eventually differ among wintering areas due to differences in wind conditions (Daunt et al. 2014) or in diel vertical migration patterns of prey (Dias et al. 2012), potentially introducing a bias in the activity patterns found in treatment and control birds. Nevertheless, since these two groups did not differ in the use of the different wintering areas (Fig. 1), potential changes in activity patterns among wintering areas would equally affect both groups of birds and therefore no bias derived from these differences should be expected to affect our study.

\section{Carryover effects of breeding on the stress condition of individuals}

In general, breeding effort and success are well-known stressors on long-lived species, and CORT levels quantified in specific tissues are often reported as a measurable proxy for the severity of such stressful responses (Bortolotti et al. 2008, Harris et al. 2017). Several recent studies on seabirds have reported on effects of breeding performances on the physiological stress that individuals experienced in different periods along the annual cycle by measuring the CORT concentration in specific feathers (Schultner et al. 2014, Sorenson et al. 2017, Young et al. 2017). Other studies, however, did not detect relevant effects of breeding on the stress condition of the individuals (Bourgeon et al. 2014, Pérez et al. 2016). Finally, and to the best of our knowledge, only one study has considered sampling the same individuals in different periods (Young et al. 2017). In our opinion, this prevents most previous research from drawing conclusions on the durability/persistence of such carryover effects.

In our experiment, we sampled two feathers, P1 molted at the breeding grounds at the end of the breeding season and S13 molted at the wintering grounds. First, birds showed higher levels of CORT during the breeding season (i.e., in the P1 feather), possibly reflecting the recent impact of the breeding effort. Second, successful breeders were expected to show higher CORT levels than failed breeders, presumably as their parental duties and effort were also higher. Interestingly, the effect of breeding performance on CORT levels was found in both seasons (i.e., there was no relevant interaction between breeding success and feather type), suggesting the stressful effects of breeding may be physiologically mediated by CORT along the entire subsequent non-breeding period. In this regard, we did not identify any direct effect of breeding effort on any relevant aspect studied 
here, but higher CORT levels in successful breeders during winter may eventually impact on more subtle traits not addressed in the present study. For instance, it may influence physiological metabolites derived from fat/protein metabolism (Navarro et al. 2008), hematological health state (Pusch et al. 2018), telomere length (Young et al. 2017), and/or diverse enzyme activities (Navarro et al. 2008, Lecomte et al. 2010), which could be eventually measured in blood samples obtained during winter or immediately after returning to the breeding colonies. Finally, we did not find any relevant effect of the migratory strategy performed by birds on the CORT concentration of feathers, although many other studies reported on them. Indeed, Pérez et al. (2016) reported on significant differences in CORT concentrations of winter feathers according to the migratory strategy of Cory's shearwater individuals. We suggest, as discussed below, that the stochasticity of the environmental conditions that individuals might face in distinct wintering areas and in different annual cycles (i.e., years of sampling; Appendix S1: Fig. S4) could blur consistent results among similar studies on hormonal responses (Wingfield 2013).

\section{Carryover effects of breeding on migration patterns}

Currently, there is a number of studies reporting carryover effects of breeding effort in both long-lived species and short-lived species, and virtually no studies reporting the absence of these effects (Table 1). In these studies, it is assumed that failed (and sabbatical) breeders are in better body condition at the end of the breeding period, and may thus have more energy (and time) at their disposal to migrate earlier and seek better wintering grounds than successful breeders. However, life history theory predicts long-lived species should not invest too heavily in a single breeding event, since this may compromise their survival and their future breeding attempts (Stearns 1992). Consequently, in these species we should not expect relevant impacts of breeding effort on the subsequent non-breeding periods or breeding events. In our case, we found no differences in the migratory behavior or subsequent breeding success between successful birds and those in which we induced breeding failure. The two groups did not differ in their foraging areas in the late breeding period or migratory destinations (Fig. 1). In addition, no statistical difference was observed in the timing of any of the phenological events we considered (Fig. 2). In contrast, Catry et al. (2013a), in a similar experiment carried out in 2009-2010, found both spatial and temporal differences in the distribution of failed and successful breeders of a nearby colony of Cory's shearwaters, even with smaller sample sizes. However, it may be that carryover effects in long-lived species are only apparent in years of poor environmental conditions (Appendix S1: Fig. S4). Thus, environmental stochasticity could play a major role in the strength of the carryover effects and ultimately on the migratory decisions taken by the individuals of different breeding status. Indeed, differences in the non-breeding distribution between failed and successful breeders are far from universal (Phillips et al. 2005, 2007, Hedd et al. 2012, Clay et al. 2016), further suggesting that carryover effects may be apparent only in specific years or breeding colonies with very unfavorable environment conditions (Bogdanova et al. 2017).

\section{Conclusions and Perspectives}

Our experimental design enabled us to overcome the problems of covariation between a natural breeding failure and the presumably low quality of the individuals that usually fail, and allowed us to test the effects of a reduced breeding effort per se in a species with a very slow pace of life, the Cory's shearwater. By combining geolocation, activity and isotopic data of such a long-lived Procellariiform, we not only unraveled the general molting pattern in relation to migration, but also provided clear insights into how the cost of breeding effort can carry over to the non-breeding period, delaying molting patterns. We also found that successful breeders experienced more stressful conditions, as indicated by the levels of CORT in their feathers, in both feathers grown at the end of the breeding season but also in those grown at the end of the wintering period. This indicated a long-lasting effect of the breeding effort throughout the entire non-breeding period. However, we did not detect any significant effect of breeding effort on migratory behavior (i.e., distribution and phenology), suggesting that birds rapidly buffered these effects after breeding, as would be expected in a long-lived species. Our results surprisingly differed from what has been usually reported in other longlived seabirds, and even in the same species (Catry et al. $2013 a$, Pérez et al. 2016). In this regard, these inconsistencies also highlighted the importance of considering environmental stochasticity while assessing potential carryover effects and the need for considering multi-year and multilocality experiments to ascertain such influences.

\section{ACKNOWLEDGMENTS}

We thank Consejería de Medio Ambiente del Cabildo de Gran Canaria for permission to conduct the experiments. We also thank the Ministerio de Ciencia e Innovación (MINECO) and Ministerio de Economía y Competitividad and Fondos FEDER (CGL200911278/BOS and CGL2013-42585-P) and the European Union (FP7PEOPLE-2013-CIG, 618841) for funding this research, and José Manuel de los Reyes, Zuzana Zajková, Pascual Calabuig and Teresa Militão for help at various stages of the work. RR was supported by postdoctoral contracts of the Beatriu de Pinós and Juan de la Cierva programs, from the Catalan AGAUR agency (2010-BPA-00173) and the Spanish MINECO (JCI-2012-11848), respectively.

\section{Literature Cited}

Aharon-Rotman, Y., K. L. Buchanan, M. Klaassen, and W. A. Buttemer. 2017. An experimental examination of interindividual variation in feather corticosterone content in the house sparrow, Passer domesticus in southeast Australia. General and Comparative Endocrinology 244:93-100.

Alonso, H., R. Matias, J. P. Granadeiro, and P. Catry. 2009. Moult strategies of Cory's Shearwaters Calonectris diomedea borealis: the influence of colony location, sex and individual breeding status. Journal of Ornithology 150:329-337.

Angelier, F., C. Clément-Chastel, G. Wing, and O. Chastel. 2007. Corticosterone and time - activity budget: an experiment with Black-legged kittiwakes. Hormones and Behavior 52:482-491.

Barta, Z., J. M. McNamara, A. I. Houston, T. P. Weber, A. Hedenström, and O. Feró. 2008. Optimal moult strategies in migratory birds. Philosophical Transactions of the Royal Society B 363:211229.

Bartoń, K. 2017. MuMIn: multi-model inference. R package version 1.40.0. https://cran.r-project.org/web/packages/MuMIn/MuMIn. pdf 
Bates, D., M. Maechler, and B. Bolker. 2017. lme4: linear mixedeffects models using "Eigen" and S4. R package version 1.1-15. https://cran.r-project.org/web/packages/lme4/lme4.pdf

Bogdanova, M. I., F. Daunt, M. Newell, R. A. Phillips, M. P. Harris, and S. Wanless. 2011. Seasonal interactions in the blacklegged kittiwake, Rissa tridactyla: links between breeding performance and winter distribution. Proceedings of the Royal Society of London B: Biological Sciences 278:2412-2418.

Bogdanova, M. I., et al. 2017. Multi-colony tracking reveals spatiotemporal variation in carryover effects between breeding success and winter movements in a pelagic seabird. Marine Ecology Progress Series 578:167-181.

Bortolotti, G. R., T. A. Marchant, J. Blas, and T. German. 2008. Corticosterone in feathers is a long-term, integrated measure of avian stress physiology. Functional Ecology 22:494-500.

Boulinier, T., K. D. McCoy, N. G. Yoccoz, J. Gasparini, and T. Tveraa. 2008. Public information affects breeding dispersal in a colonial bird: kittiwakes cue on neighbours. Biology Letters 4:538-540.

Bourgeon, S., E. H. K. Leat, E. Magnusdóttir, R. W. Furness, H Strøm, A. Petersen, G. W. Gabrielsen, S. A. Hanssen, and J. O. Bustnes. 2014. Feather corticosterone levels on wintering grounds have no carryover effects on breeding among three populations of great skuas (Stercorarius skua). PLoS ONE 9:1-6.

Bridge, E. S. 2006. Influences of morphology and behavior on wingmolt strategies in seabirds. Marine Ornithology 34:7-19.

Calenge, C. 2006. The package "adehabitat" for the R software: a tool for the analysis of space and habitat use by animals. Ecological Modelling 197:516-519.

Carbajal, A., O. Tallo-Parra, M. Sabes-Alsina, I. Mular, and M. Lopez-Bejar. 2014. Feather corticosterone evaluated by ELISA in broilers: a potential tool to evaluate broiler welfare. Poultry Science 93:2884-2886.

Catry, P., M. P. Dias, R. A. Phillips, and J. P. Granadeiro. 2013a. Carryover effects from breeding modulate the annual cycle of a long-distance migrant: an experimental demonstration. Ecology 94:1230-1235.

Catry, P., M. Poisbleau, M. Lecoq, and R. A. Phillips. 2013b. Differences in the timing and extent of annual moult of black-browed albatrosses Thalassarche melanophris living in contrasting environments. Polar Biology 36:837-842.

Cherel, Y., P. Quillfeldt, K. Delord, and H. Weimerskirch. 2016. Combination of at-sea activity, geolocation and feather stable isotopes documents where and when seabirds molt. Frontiers in Ecology and Evolution 4:3.

Clay, T. A., A. Manica, P. G. Ryan, J. R. D. Silk, J. P. Croxall, L. Ireland, and R. A. Phillips. 2016. Proximate drivers of spatial segregation in non-breeding albatrosses. Scientific Reports 6: 29932.

Crossin, G. T., S. J. Cooke, J. A. Goldbogen, and R. A. Phillips. 2014. Tracking fitness in marine vertebrates: current knowledge and opportunities for future research. Marine Ecology Progress Series 496:1-17.

Crossin, G. T., R. A. Phillips, C. R. Lattin, L. M. Romero, X. Bordeleau, C. M. Harris, O. P. Love, and T. D. Williams. 2017. Costs of reproduction and carryover effects in breeding albatrosses. Antarctic Science 29:155-164.

Daunt, F., V. Afanasyev, J. R. D. Silk, and S. Wanless. 2006. Extrinsic and intrinsic determinants of winter foraging and breeding phenology in a temperate seabird. Behavioral Ecology and Sociobiology 59:381-388.

Daunt, F., T. E. Reed, M. Newell, S. Burthe, R. A. Phillips, S. Lewis, and S. Wanless. 2014. Longitudinal bio-logging reveals interplay between extrinsic and intrinsic carryover effects in a long-lived vertebrate. Ecology 95:2077-2083.

Dawson, A., S. A. Hinsley, P. N. Ferns, R. H. Bonser, and L. Eccleston. 2000. Rate of moult affects feather quality: a mechanism linking current reproductive effort to future survival. Proceedings of the Royal Society of London B: Biological Sciences 267:20932098 .
Dias, M. P., J. P. Granadeiro, and P. Catry. 2012. Working the day or the night shift? Foraging schedules of Cory's shearwaters vary according to marine habitat. Marine Ecology Progress Series 467:245-252.

Dias, M. P., J. P. Granadeiro, R. A. Phillips, H. Alonso, and P. Catry. 2011. Breaking the routine: individual Cory's shearwaters shift winter destinations between hemispheres and across ocean basins. Proceedings of the Royal Society of London B: Biological Sciences 278:1786-1793.

Edwards, A. E. 2008. Large-scale variation in flight feather molt as a mechanism enabling biennial breeding in albatrosses. Journal of Avian Biology 39:144-151.

Fairhurst, G. D., L. Champoux, K. A. Hobson, J. F. Rail, J. Verreault, M. Guillemette, W. A. Montevecchi, P. Brousseau, and C. Soos. 2017. Feather corticosterone during non-breeding correlates with multiple measures of physiology during subsequent breeding in a migratory seabird. Comparative Biochemistry and Physiology, Part A 208:1-13. https://doi.org/10.1016/j.cbpa.2017.02.024

Fayet, A. L., R. Freeman, A. Shoji, H. L. Kirk, O. Padget, C. M. Perrins, T. Guilford, and S. Verhulst. 2016. Carryover effects on the annual cycle of a migratory seabird: an experimental study. Journal of Animal Ecology 85:1516-1527.

Fox, J. 2015. Intiproc geolocation processing software. User reference manual Intiproc v1.03. Migrate Technology Ltd, Cambridge, UK.

Garthe, S., K. Ludynia, O. Hüppop, U. Kubetzki, J. F. Meraz, and R. W. Furness. 2012. Energy budgets reveal equal benefits of varied migration strategies in northern gannets. Marine Biology 159:1907-1915.

Golet, G. H., J. A. Schmutz, D. B. Irons, and J. A. Estes. 2004. Determinants of reproductive costs in teh long-lived Black-legged kittiwake: a multiyear experiment. Ecological Monographs 74: 353-372.

González-Solís, J., J. P. Croxall, D. Oro, and X. Ruiz. 2007. Trans-equatorial migration and mixing in the wintering areas of a pelagic seabird. Frontiers in Ecology and the Environment 5: 297-301.

Harms, N. J., P. Legagneux, H. G. Gilchrist, O. P. Love, M. R. Forbes, G. R. Bortolotti, and C. Soos. 2015. Feather corticosterone reveals effect of moulting conditions in the autumn on subsequent reproductive output and survival in an Arctic migratory bird. Proceedings of the Royal Society B 282:20142085.

Harris, C. M., C. L. Madliger, and O. P. Love. 2017. An evaluation of feather corticosterone as a biomarker of fitness and an ecologically relevant stressor during breeding in the wild. Oecologia 183:987-996.

Harrison, X. A., J. D. Blount, R. Inger, D. R. Norris, and S. Bearhop. 2011. Carryover effects as drivers of fitness differences in animals. Journal of Animal Ecology 80:4-18.

Hastie, T., and R. Tibshirani. 1990. Generalized additive models. Chapman \& Hall/CRC, London, UK.

Hedd, A., W. Montevecchi, H. Otley, R. A. Phillips, and D. A. Fifield. 2012. Trans-equatorial migration and habitat use by sooty shearwaters Puffinus griseus from the South Atlantic during the nonbreeding season. Marine Ecology Progress Series 449:277-290.

Inger, R., X. A. Harrison, G. D. Ruxton, J. Newton, K. Colhoun, G. A. Gudmundsson, G. McElwaine, M. Pickford, D. Hodgson, and S. Bearhop. 2010. Carry-over effects reveal reproductive costs in a long-distance migrant. Journal of Animal Ecology 79:974 982. https://doi.org/10.1111/j.1365-2656.2010.01712.x

Jackson, A. L., R. Inger, A. C. Parnell, and S. Bearhop. 2011. Comparing isotopic niche widths among and within communities: SIBER-Stable Isotope Bayesian Ellipses in R. Journal of Animal Ecology 80:595-602.

Jenni-eiermann, S., F. Helfenstein, A. Vallat, and L. Jenni. 2015. Corticosterone: effects on feather quality and deposition into feathers. Methods in Ecology and Evolution 6:237-246.

Johnson, J. B., and K. S. Omland. 2004. Model selection in ecology and evolution. Trends in Ecology \& Evolution 19:101-108.

Kitaysky, A. S., E. V. Kitaiskaia, J. C. Wingfield, and J. F. Piatt. 2001. Dietary restriction causes chronic elevation of 
corticosterone and enhances stress response in red-legged kittiwake chicks. Journal of Comparative Physiology B 171:701-709.

Kitaysky, A. S., J. F. Piatt, S. A. Hatch, E. V. Kitaiskaia, Z. M. Benowitz-Fredericks, M. T. Shultz, and J. C. Wingfield. 2010. Food availability and population processes: severity of nutritional stress during reproduction predicts survival of long-lived seabirds. Functional Ecology 24:625-637.

Lascelles, B. G., et al. 2016. Applying global criteria to tracking data to define important areas for marine conservation. Diversity and Distributions 22:422-431.

Lecomte, V. J., et al. 2010. Patterns of aging in the long-lived wandering albatross. Proceedings of the National Academy of Sciences USA 107:6370-6375.

Lindén, M., and A. P. Moller. 1989. Cost of reproduction and covariation of life history traits in birds. Trends in Ecology and Evolution 4:367-371.

Lindström, J. 1999. Early development and fitness in birds and mammals. Trends in Ecology \& Evolution 14:343-348.

McConnell, B. J., C. Chambers, and M. A. Fedak. 1992. Foraging ecology of southern elephant seals in relation to the bathymetry and productivity of the Southern Ocean. Antarctic Science 4:393-398.

Meier, R. E., et al. 2017. Tracking, feather moult and stable isotopes reveal foraging behaviour of a critically endangered seabird during the non-breeding season. Diversity and Distributions 23:130-145.

Metcalfe, N. B., and P. Monaghan. 2001. Compensation for a bad start: Grow now, pay later? Trends in Ecology \& Evolution 16:254-260.

Mitchell, G. W., A. E. M. Newman, M. Wikelski, and D. R. Norris. 2012. Timing of breeding carries over to influence migratory departure in a songbird: an automated radiotracking study. Journal of Animal Ecology 81:1024-1033.

Monteiro, L. R., and R. W. Furness. 1996. Molt of Cory's shearwater during the breeding season. Condor 98:216-221.

Navarro, J., J. González-Solís, G. Viscor, and O. Chastel. 2008. Ecophysiological response to an experimental increase of wing loading in a pelagic seabird. Journal of Experimental Marine Biology and Ecology 358:14-19.

Nilsson, J.-A., and E. Svensson. 1996. The cost of reproduction: a new link between current reproductive effort and future reproductive success. Proceedings of the Royal Society of London B: Biological Sciences 263:711-714.

Norris, D. R., and P. P. Marra. 2007. Seasonal interactions, habitat quality, and population dynamics in migratory birds. Condor 109:535-547.

Norris, D. R., P. P. Marra, R. Montgomerie, T. K. Kyser, and L. M. Ratcliffe. 2004. Reproductive effort, molting latitude, and feather color in a migratory songbird. Science 306:2249-2251.

Pérez, C., J. P. Granadeiro, M. P. Dias, and P. Catry. 2016. Sex and migratory strategy influence corticosterone levels in winter-grown feathers, with positive breeding effects in a migratory pelagic seabird. Oecologia 181:1025-1033.

Phillips, R. A., P. Catry, J. R. D. Silk, S. Bearhop, R. McGill, V. Afanasyev, and I. J. Strange. 2007. Movements, winter distribution and activity patterns of Falkland and brown skuas: insights from loggers and isotopes. Marine Ecology Progress Series 345:281-291.

Phillips, R. A., J. R. D. Silk, J. P. Croxall, V. Afanasyev, and D. R. Briggs. 2004. Accuracy of geolocation estimates for flying seabirds. Marine Ecology Progress Series 266:265-272.

Phillips, R. A., J. R. D. Silk, J. P. Croxall, V. Afanasyev, and V. J. Bennett. 2005. Summer distribution and migration of nonbreeding albatrosses: individual consistencies and implications for conservation. Ecology 86:2386-2396.

Phillips, R. A., J. C. Xavier, and J. P. Croxall. 2003. Effects of satellite transmitters on albatrosses and petrels. Auk 120:1082-1090.
Pinheiro, J. C., and D. M. Bates. 2000. Mixed-effects models in S and S-PLUS. Springer Verlag, New York, New York, USA.

Pusch, E. A., A. B. Bentz, D. J. Becker, and K. J. Navara. 2018. Behavioral phenotype predicts physiological responses to chronic stress in proactive and reactive birds. General and Comparative Endocrinology 255:71-77.

R Development Core Team. 2017. R: a language and environment for statistical computing. R Foundation for Statistical Computing, Vienna, Austria. http://www.rproject.org

Ramos, R., J. P. Granadeiro, M. Nevoux, J.-L. Mougin, M. P. Dias, and P. Catry. 2012. Combined spatio-temporal impacts of climate and longline fisheries on the survival of a trans-equatorial marine migrant. PLoS ONE 7:e40822.

Ramos, R., J. González-Solís, and X. Ruiz. 2009a. Linking isotopic and migratory patterns in a pelagic seabird. Oecologia 160:97-105.

Ramos, R., T. Militão, J. González-Solís, and X. Ruiz. $2009 b$. Moulting strategies of a long-distance migratory seabird, the Mediterranean Cory's Shearwater Calonectris diomedea diomedea. Ibis 151:151-159.

Romero, L. M. 2004. Physiological stress in ecology: lessons from biomedical research. Trends in Ecology and Evolution 19:249-255.

Runge, M. C., and P. P. Marra. 2005. Modelling seasonal interactions in the population dynamics of migratory birds. Pages 375389 in R. Greenberg and P. P. Marra, editors. Birds of two worlds: the ecology and evolution of migration. Johns Hopkins University Press, Baltimore, Maryland, USA.

Rushing, C. S., J. A. Hostetler, T. S. Sillett, P. P. Marra, J. A. Rotenberg, and T. B. Ryder. 2017. Spatial and temporal drivers of avian population dynamics across the annual cycle. Ecology 98:2837-2850.

Schultner, J., B. Moe, O. Chastel, S. Tartu, C. Bech, and A. S. Kitaysky. 2014. Corticosterone mediates carryover effects between breeding and migration in the kittiwake Rissa tridactyla. Marine Ecology Progress Series 496:125-133.

Shaffer, S. A., D. P. Costa, and H. Weimerskirch. 2001. Behavioural factors affecting foraging effort of breeding wandering albatrosses. Journal of Animal Ecology 70:864-874.

Sink, T. D., R. T. Lochmann, and K. A. Fecteau. 2008. Validation, use, and disadvantages of enzyme-linked immunosorbent assay kits for detection of cortisol in channel catfish, largemouth bass, red pacu, and golden shiners. Fish Physiology and Biochemistry 34:95-101.

Sorenson, G. H., C. J. Dey, C. L. Madliger, and O. P. Love. 2017. Effectiveness of baseline corticosterone as a monitoring tool for fitness: a meta-analysis in seabirds. Oecologia 183:353-365.

Stearns, S. C. 1992. The evolution of life histories. Oxford University Press, Oxford, UK.

Stutchbury, B. J., E. A. Gow, T. Done, M. MacPherson, J. W. Fox, and V. Afanasyev. 2011. Effects of post-breeding moult and energetic condition on timing of songbird migration into the tropics. Proceedings Of The Royal Society B-Biological Sciences 278:131137. https://doi.org/10.1098/rspb.2010.1220

Thibault, J. C., V. Bretagnolle, and C. Rabouam. 1997. Cory's shearwater. BWP Update (The Journal of the Birds of the Western Palearctic) 1:75-98.

Wingfield, J. C. 2013. Ecological processes and the ecology of stress: the impacts of abiotic environmental factors. Functional Ecology 27:37-44.

Wood, S. N., and N. H. Augustin. 2002. GAMs with integrated model selection using penalized regression splines and applications to environmental modelling. Ecological Modelling 157:157-177.

Young, R. C., R. A. Orben, A. P. Will, and A. S. Kitaysky. 2017. Relationship between telomere dynamics and movement and behavior during winter in the thick-billed murre. Marine Ecology Progress Series 578:253-261.

\section{SUPPORTING INFORMATION}

Additional supporting information may be found in the online version of this article at http://onlinelibrary.wiley.com/doi/10.1002/ecy. 2435/suppinfo 